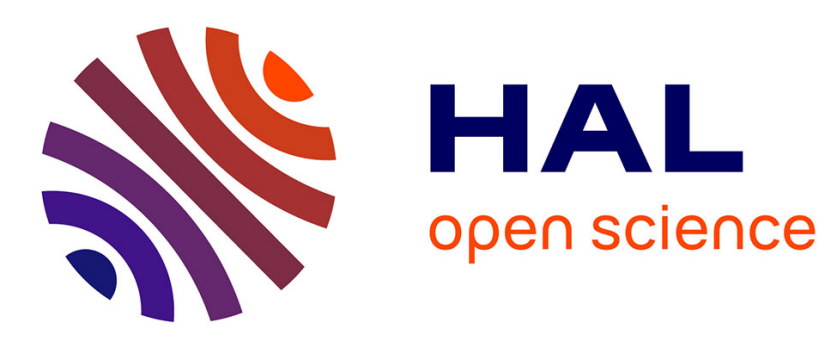

\title{
Hydromechanical modeling of granular soils considering internal erosion
}

\author{
Jie Yang, Zhen-Yu Yin, Farid Laouafa, Pierre-Yves Hicher
}

\section{To cite this version:}

Jie Yang, Zhen-Yu Yin, Farid Laouafa, Pierre-Yves Hicher. Hydromechanical modeling of granular soils considering internal erosion. Canadian Geotechnical Journal, 2020, 57 (2), pp.157-172. 10.1139/cgj-2018-0653 . ineris-03319074

\section{HAL Id: ineris-03319074 \\ https://hal-ineris.archives-ouvertes.fr/ineris-03319074}

Submitted on 11 Aug 2021

HAL is a multi-disciplinary open access archive for the deposit and dissemination of scientific research documents, whether they are published or not. The documents may come from teaching and research institutions in France or abroad, or from public or private research centers.
L'archive ouverte pluridisciplinaire HAL, est destinée au dépôt et à la diffusion de documents scientifiques de niveau recherche, publiés ou non, émanant des établissements d'enseignement et de recherche français ou étrangers, des laboratoires publics ou privés. 
2 Author 1

3 Jie $\mathrm{YANG}, \mathrm{PhD}$ candidate

4 INERIS, Verneuil en Halatte, France; Research Institute of Civil Engineering and Mechanics (GeM),

5 UMR CNRS 6183, Ecole Centrale de Nantes, France.

$6 \quad$ Email: doc.jie.yang@gmail.com

7 Author 2

8 Zhen-Yu YIN*, Associate Professor

9 Department of Civil and Environmental Engineering, The Hong Kong Polytechnic University, Hung

10 Hom, Kowloon, Hong Kong, China.

11 Email: zhenyu.yin@polyu.edu.hk,zhenyu.yin@gmail.com

12 Author 3

13 Farid LAOUAFA, $\mathrm{PhD}$

14 INERIS, Verneuil en Halatte, France.

15 Email: farid.laouafa@ineris.fr

\section{Author 4}

17 Pierre-Yves HICHER, Emeritus Professor

18 Research Institute of Civil Engineering and Mechanics (GeM), UMR CNRS 6183, Ecole Centrale de

19 Nantes, France.

20 Email: pierre-yves.hicher@ec-nantes.fr

$21 *$ Corresponding author:

22 Zhen-Yu YIN, Tel: +852 3400 8470; Fax: +852 2334 6389; Email: zhenyu.yin@polyu.edu.hk,

23 zhenyu.yin@gmail.com 


\section{Abstract:}

28 This paper attempts to formulate a coupled practical model in the framework of continuum

29 mechanics to evaluate the phenomenon of internal erosion and its consequences on the mechanical

30 behavior of soils. For this purpose, a four-constituent numerical approach has been developed to

31 describe the internal erosion process. The detachment and transport of the fine particles have been

32 described by a mass exchange formulation between the solid and fluid phases. The stress-strain

33 relationship of the soil is represented by a non-linear incremental model. Based on experimental data,

34 this constitutive model has been enhanced by the introduction of a fines content dependent critical

35 state, which allows accounting for the influence of fines on soil deformation and strength. The

36 applicability of the practical approach to capture the main features of the internal erosion process and

37 its impact on the mechanical behavior of the eroded soil has been validated by comparing numerical

38 and experimental results of internal erosion tests on HK-CDG mixtures, which demonstrated that the

39 practical model was able to reproduce, with a reasonable success, the experimental data.

40 Furthermore, the influence of the stress state, the initial soil density, and the initial fraction of fines

41 have been analyzed through numerical simulations using the proposed model.

42 Keywords: Granular soils; internal erosion; hydro-mechanical coupling; critical state; fines content 


\section{1. Introduction}

45 Internal erosion occurs when fine particles are plucked off by hydraulic forces and transported

46 through the coarse matrix. The known causes are either a concentration of leak erosion, backward

47 erosion, soil contact erosion, or suffusion (Bonelli and Marot 2008; Fell et al. 2003; Wan and Fell

48 2004). This paper focuses on suffusion, which corresponds to the detachment and migration of fine

49 particles within the voids of coarse particles by seepage flow. Subsequently, the induced

50 modification of the soil microstructure may lead to deformations at the macroscopic scale and,

51 therefore, influence significantly the mechanical behavior of the soil. Many damages and failures of

52 embankment dams can be associated with internal erosion (Fell et al. 2003; Xu and Zhang 2009;

53 Zhang and Chen 2006; Zhang et al. 2009; Rönnqvist et al. 2014). Foster et al. (2000) showed that

54 nearly $46 \%$ of the damages of 128 embankment dams could be attributed to internal erosion.

55 Besides, sinkholes and cavities triggered by internal erosion are frequently observed within dams and

56 dikes (Muir Wood 2007; Sterpi 2003). Finally, internal erosion can also trigger slope failures and

57 generate significant landslides (Crosta and Prisco 1999; Hu et al. 2018).

58 To evaluate the internal instability of filters in embankment dam, engineers have traditionally

59 employed empirical methods (Burenkova 1993; Foster and Fell 2001; Kenney and Lau 1985, 1986;

60 Kézdi 1979; Li and Fannin 2008; Sherard 1979; Wan and Fell 2008). Rönnqvist et al. (2014)

61 compiled a database of 80 dams of which 23 dams suffered from documented internal erosion. Their

62 gradation analysis demonstrated that empirical methods are capable of distinguishing dams with a

63 probable occurrence of erosion from dams with no up-to-date indication of internal erosion.

64 Laboratory tests further investigated the mechanics of internal erosion and the susceptibility of soil to

65 seepage induced internal instability by using primarily the conventional rigid-walled permeameter

66 under self-weight conditions (e.g. Kenney and Lau 1985, Skempton and Brogan 1994, Sterpi 2003,

67 Wan and Fell 2008, Sibille et al. 2015a; Rochim et al. 2017). The eroded mass, the hydraulic 
68 gradient and the flow rate were monitored to determine the susceptibility of seepage induced

69 instability by incorporating the post-erosion analysis of the particle size distribution. The initial fines

70 content and the history of the hydraulic loading appeared to play an important role in the

71 development of internal erosion (Sibille et al. 2015a; Rochim et al. 2017). It is important to add that

72 the soils constituting embankment dams or levees are usually subjected to complex stress states

73 (Zhang and Du 1997). To address this phenomenon, Moffat and Fannin $(2006,2011)$ developed a

74 rigid-wall permeameter with an axial loading system so that the onset of internal instability of

75 cohesionless soils under $K_{0}$ stress state could be investigated. More recently, advanced flexible wall

76 permeameters capable of controlling the stress on the tested specimen have been developed so that

77 the development of internal erosion under different stress states and the mechanical behavior of soils

78 during and after erosion could be investigated (e.g., Bendahmane et al. 2008; Chang and Zhang

79 2011; Marot et al. 2016; Ke and Takahashi 2014a; Slangen and Fannin 2016). Most of the studies

80 were conducted under an isotropic stress state. The results showed that the larger effective confining

81 pressure led to a less extent of internal erosion (Bendahmane et al. 2008; Mehdizadeh et al. 2017),

82 even if the deformation of the specimen caused by erosion was limited. Chang and Zhang (2011)

83 showed that, by performing internal erosion tests under different anisotropic stress states, the

84 maximum erosion rate, the variations in soil permeability, and the erosion induced deformation of

85 the specimen will all increase with the increase of the deviatoric stress. For the purpose of

86 investigating the influence of the loss of fine particles on the mechanical behavior of eroded soils,

87 they performed triaxial tests on eroded specimen under different stress paths. Drained triaxial tests

88 on eroded specimens indicated that the initially dilative stress-strain behavior changed to a

89 contractive behavior and the soil strength decreased under drained shearing (Chang and Zhang 2011;

90 Ke and Takahashi 2014a, 2014b, 2015). The undrained behavior of the original specimen changed

91 from a strain hardening behavior to a flow-type behavior with limited deformation after internal

92 erosion (Ke et al. 2016; Mehdizadeh et al. 2017). 
93 Parallel to experimental studies, numerical approaches have also been proposed to describe the

94 erosion process, either within the framework of continuum mechanics by using finite element or

95 finite difference methods (Cividini and Gioda 2004; Papamichos et al. 2001; Stavropoulou et al.

96 1998; Vardoulakis et al. 1996; Zhang et al. 2013), or within a discrete framework by associating the

97 discrete element method to describe the dynamics of the granular solid phase to the computational

98 fluid dynamics to solve the interstitial fluid flow (Lominé et al. 2013; Mansouri et al. 2017; Reboul

99 2008; Sari et al. 2011; Sibille et al. 2015b; Zhang et al. 2018; Zhao and Shan 2013), mainly focused

100 on the hydraulic process, i.e. the evolution of the eroded mass and permeability. The mechanical part

101 was simplified by using an elastic model with induced damage parameters. Some attempts have also

102 been made to model the mechanical response to internal erosion by removing particles in granular

103 materials. Muir Wood et al. (2010) modeled the mechanical consequences of internal erosion by a

104 two-dimensional discrete element analysis and found that internal erosion changes the density state

105 of the material from dense to loose as they compared the current soil state to the critical state line.

106 Scholtès et al. (2010) developed a three-dimensional discrete element model and an analytical

107 micromechanical model to describe the mechanical responses induced by particle removal in

108 granular materials. They found that the mechanical behavior of the soil changes from dilative to

109 contractive with the removal of soil particles. However, this removal was based on the size of the

110 particles and their degree of interlocking, and the fluid phase was not considered. Hosn et al. (2018)

111 studied the macroscopic response during internal erosion and the post-internal erosion properties of

112 granular materials by particle removal, considering a one-way coupling between the fluid and the

113 solid phases via the discrete element and the pore scale finite volume methods. The erosion process

114 was simplified into the definition of the detached and transportable particles by calculating the

115 unbalance fluid force and by defining a controlling constriction size. Hicher (2013) presented a

116 numerical method to predict the mechanical behavior of granular materials subjected to particle

117 removal and concluded that the removal of soil particles may cause diffuse failure in eroded soil 
118 masses. However, the process of real erosion was not considered. Therefore, it is of interest to

119 develop a numerical method that will provide the modeling of the hydro-mechanical response of

120 soils subjected to internal erosion.

121 Despite the relevance of the discrete element method to shed light onto the constitutive properties of 122 granular materials, its computational cost remains a restrictive aspect which could become an 123 obstacle wherever real soil structures such as embankment dams are concerned. Hence, it is 124 necessary to develop the approaches that can take better into account the engineering boundary value 125 problems. The objective of this paper is to formulate a numerical model within the framework of 126 continuum mechanics to investigate the coupled hydro-mechanical behavior of soils subjected to 127 internal erosion. First, an enhanced four-constituent model has been developed to describe the 128 detachment and transport of fine particles induced by the fluid flow with more realistic consideration 129 of the effects of the fines content and the shear stress level. This process has been coupled with an 130 advanced critical state-based mechanical model, which has been enhanced to consider the effects of 131 the evolution of the fines content. By assuming a homogenous sample, a practical simulation tool for 132 triaxial erosion tests under mechanical loadings has also been proposed. Then, the predictive ability 133 of the approach has been examined by simulating internal erosion tests on HK-CDG mixtures under 134 mechanical loadings. Finally, the influence of the stress state, the initial density, and the initial fines 135 content of the soil have been investigated by the developed numerical model.

\section{2. Coupled hydro-mechanical model}

137 According to Schaufler et al. (2013), it is possible to consider the saturated porous medium as a 138 material system composed of 4 constituents in 2 phases: the stable fabric of the solid skeleton, the 139 erodible fines, the fluidized particles and the pure fluid. The fines can behave either as a fluid-like 140 (described as fluidized particles) or as a solid-like (described as erodible fines) material. 
141 It is assumed that the seepage velocities $\mathbf{w}$ is given as the relative motion of the fluid phase $\mathbf{v}_{l}$ with

142 respect to the solid phase $\mathbf{v}_{s}$. The relative motion of the pore fluid and the fluidized particles is

143 neglected. The total discharge of the liquid $\mathbf{q}_{w}$ is then given as:

$$
\mathbf{q}_{w}(x, t)=\phi(x, t) \mathbf{w}(x, t) \text { with } \mathbf{w}(x, t)=\mathbf{v}_{l}-\mathbf{v}_{s}
$$

145 where $\phi(x, t)$ is the porosity. Furthermore, in the framework of small transformations (small strains

146 and small displacements), the strain of the solid skeleton is given by the symmetric part of the

147 displacement gradient.

\section{2.1. Mass balances and transported particles}

149 The balance equations are derived based on the porous medium theory (de Boer 2000; Steeb and 150 Diebels 2003; Uzuoka and Borja 2012). The local form of the volume balance of a constituent is 151 deduced from the partial balance of mass (Vardoulakis et al. 1996), given as:

$$
\frac{\partial\left(n_{i}\right)}{\partial t}+\operatorname{div}\left(n_{i} \mathbf{v}_{i}\right)=\hat{n}
$$

153 where $n_{i}$ and $\mathbf{v}_{i}$ denote, respectively, the volume fraction and the velocity of the corresponding

154 constituent. The liquid-solid phase transition process has been accounted for by introducing a 155 volumetric mass exchange term $\hat{n}$ in the corresponding mass balances for the 4 constituents. More 156 details can be found in the Appendix A1.

157 A system of non-linear partial differential equations is deduced from the mass balance of the mixture 158 system:

$$
\operatorname{div}\left(\mathbf{q}_{w}\right)+\operatorname{div}\left(\mathbf{v}_{s}\right)=0
$$




$$
\frac{\partial\left(f_{c}\right)}{\partial t}-\frac{\partial\left(f_{c} \phi\right)}{\partial t}+\operatorname{div}\left(f_{c} \mathbf{v}_{s}\right)-\operatorname{div}\left(f_{c} \phi \mathbf{v}_{s}\right)=\hat{n}
$$

$$
\frac{\partial(c \phi)}{\partial t}+\operatorname{div}\left(c \mathbf{q}_{\mathbf{w}}\right)+\frac{\partial\left(c \phi \mathbf{v}_{s}\right)}{\partial t}=-\hat{n}
$$

163 where $\phi(x, t), f_{c}(x, t)$ and $c(x, t)$ are the porosity, the amount of erodible fines and the

164 concentration of the fluidized particles, respectively; $\hat{n}$ is the source term describing the exchange 165 between the erodible fines and the fluidized particles; $\mathbf{v}_{s}$ is the velocity of the soil skeleton; $\mathbf{q}_{w}(x, t)$ 166 is the total discharge of the pore fluid.

\subsection{Balance of linear momentum}

168 The model has been developed for geotechnical applications and it is not the aim of the present paper 169 to present the thermodynamical setting of the erosion model. Therefore, the linear momentum 170 balance equation of a constituent is given as follows under isothermal and quasi-static conditions:

$$
\operatorname{div}\left(\boldsymbol{\sigma}_{i}\right)+\hat{\mathbf{p}}_{i}=0, \sum_{i} \hat{\mathbf{p}}_{i}=0
$$

172 where $\boldsymbol{\sigma}_{i}$ is the total Cauchy stress tensor of the solid or liquid phase; $\hat{\mathbf{p}}_{i}$ is the interaction force

173 between solid and liquid phases. In this configuration, further density driven momentum production 174 (see Steeb and Diebels 2003) and body forces are not taken into account. Nevertheless, we assume 175 that the process is slow, i.e. the inertia forces can be neglected. This equilibrium equation allows 176 prescribing the total force $\mathbf{t}=\boldsymbol{\sigma} \cdot \mathbf{n}$ and the solid displacement $\mathbf{u}_{s}$ at the boundary of the body. 
177 The partial Cauchy stresses $\boldsymbol{\sigma}_{i}$ for the two phases are derived as follows for a fluid saturated medium 178 (Borja 2006):

$$
\boldsymbol{\sigma}_{s}=\boldsymbol{\sigma}^{\prime}-(1-\phi) p_{w} \mathbf{I}, \boldsymbol{\sigma}_{l}=-\phi p_{w} \mathbf{I}
$$

180 where $\boldsymbol{\sigma}^{\prime}$ is the effective stress tensor, calculated by the non-linear incremental constitutive model 181 presented in the next section; $p_{w}$ is the pore fluid pressure. Thus the set of equations (3)-(6) can be 182 closed by:

$$
\operatorname{div}\left(\boldsymbol{\sigma}^{\prime}-p_{w} \mathbf{I}\right)=0
$$

\section{$184 \quad$ 2.3. Porous fluid flow}

185 In this study, it is assumed that the flow in the porous medium is governed by Darcy's law which 186 states that the flow rate is driven by the gradient of the pore fluid pressure $p_{w}(x, t)$ :

$$
\mathbf{q}_{\mathbf{w}}=-\frac{k\left(f_{c}, \phi\right)}{\eta_{k} \bar{\rho}(c)} \operatorname{grad}\left(p_{w}\right)
$$

188 where $k\left(f_{c}, \phi\right)$ denotes the intrinsic permeability of the medium; $\eta_{k}$ is the kinematic viscosity of the

189 fluid; $p_{w}$ is the pore fluid pressure; and $\bar{\rho}(c)$ is the density of the mixture defined as:

$$
\bar{\rho}=c \rho_{s}+(1-c) \rho_{f}
$$

191 with $\rho_{s}$ the density of the solid and $\rho_{f}$ the density of the fluid. For a material made of a mixture of 192 coarse and fine grains, the intrinsic permeability $k(x, t)$ of the porous medium depends on the 193 current porosity $\phi(x, t)$ and the fines content $f_{c}(x, t)$ as (Revil and Cathles 1999): 


$$
k=k_{0}\left[1-f_{c}(1-\phi)\right]^{3 m_{k}}
$$

195 where $m_{k}$ is a power index which varies with the pore geometry (Revil and Cathles 1999).

\section{2.4. Mass exchange term}

197 The variable $\hat{n}$ in Eqs. (4)-(6) is the volumetric mass exchange at any point in time, given by the 198 following relation (Uzuoka et al. 2012):

$$
\hat{n}=-\lambda_{e}(1-\phi)\left(f_{c}-f_{c \infty}\right)\left|\mathbf{q}_{\mathbf{w}}\right|
$$

200 where $f_{c \infty}$ is the ultimate fines content after a long seepage period; $\lambda_{e}$ is a material parameter. The

201 erosion rate depends not only on the total discharge of fluid $\mathbf{q}_{\mathbf{w}}$, but also on the residual fines content $202\left(f_{c}-f_{c \infty}\right) \cdot f_{c \infty}$ is assumed to decrease when the hydraulic gradient increases as follows (Cividini et 203 al. 2009):

$$
f_{c \infty}=f_{c 0}\left[\left(1-\frac{\alpha_{1}}{\exp \left(\eta / M_{p}\right)}\right) \exp \left(-\left|\mathbf{q}_{\mathbf{w}}\right|^{\alpha_{3}} \times 10^{\alpha_{2}}\right)+\frac{\alpha_{1}}{\exp \left(\eta / M_{p}\right)}\right]
$$

205 where $f_{c 0}$ is the initial fines content, $\alpha_{1}, \alpha_{2}$ and $\alpha_{3}$ are material parameters. A mechanical 206 component " $\eta$ " defined later on is introduced into the definition of $f_{c \infty}$, in order to take into account 207 the influence of the stress state on the erosion rate.

208 Note that the mass exchange term $\hat{n}$ is defined as a function of the porosity, the initial fines content, 209 the flow rate and the stress state. There isn't any explicit expression to define the critical hydraulic 210 gradient required to initiate the erosion or the soil skeleton deformation. All the unknown variables 211 are coupled implicitly and solved by the system of the partial differential equations. 


\section{2.5. Critical state based soil model considering fines content effect}

213 A non-linear incremental constitutive model including the critical state concept has been adopted

214 (Yin et al. 2018a). The non-linear frictional behavior of the granular materials can be described by an

215 asymptotic relation between the stress ratio $\eta$ and the shear strain $\varepsilon_{d}$ as follows:

$$
\eta=M_{p}\left(1-e^{-\frac{G_{\eta}}{M_{p}} \varepsilon_{d}}\right)
$$

217 where $M_{p}$ is the maximum strength ratio; $G_{\eta}=3 G / p^{\prime}$ is the initial stiffness; $p^{\prime}$ is the effective

218 pressure; $G$ is the shear modulus. The model has been enhanced by introducing a non-linear 219 elasticity, a non-linear stress dilatancy, and the critical state concept (Jin et al. 2017; Jin et al. 2016; 220 Jin and Yin 2018). More details of the model can be found in Yin et al. (2018a).

221 The constitutive equations under axisymmetric triaxial condition are briefly summarized as follows:

$$
\begin{gathered}
\delta p^{\prime}=K\left\{\delta \varepsilon_{v}-A_{d}\left(M_{p t}-\frac{q}{p^{\prime}}\right) \delta \varepsilon_{d}[1-\exp (-d \eta)]\right\} \\
\delta q=3 G \delta \varepsilon_{d}\left(1-\frac{q}{p^{\prime} M_{p}}\right)+\frac{q}{p^{\prime}} \delta p^{\prime}
\end{gathered}
$$

224 with

$$
G=G_{0} \frac{(2.97-e)^{2}}{(1+e)}\left(\frac{p^{\prime}}{p_{a t}}\right)^{n}, K=K_{0} \frac{(2.97-e)^{2}}{(1+e)}\left(\frac{p^{\prime}}{p_{a t}}\right)^{n}
$$

$$
M_{p}=\frac{6 \sin \phi_{p}}{3-\sin \phi_{p}}, \quad M_{p t}=\frac{6 \sin \phi_{p t}}{3-\sin \phi_{p t}}
$$


where $\phi_{p}$ and $\phi_{p t}$ are determined by

$$
\tan \phi_{p}=\left(\frac{e_{c}}{e}\right)^{n_{p}} \tan \phi_{c}, \quad \tan \phi_{p t}=\left(\frac{e_{c}}{e}\right)^{-n_{d}} \tan \phi_{c}
$$

229 with the critical state void ratio $e_{c}$ given by

$$
e_{c}=e_{c r 0}-\lambda\left(\frac{p^{\prime}}{p_{a t}}\right)^{\xi}
$$

231 where the stress ratio $\eta=q / p^{\prime}$ under axisymmetric triaxial condition is defined by the deviatoric 232 stress $q\left(q=\sigma_{a}-\sigma_{r}\right)$ and the mean effective stress $p^{\prime}\left(p^{\prime}=\left(\sigma_{a}^{\prime}+2 \sigma_{r}^{\prime}\right) / 3\right)$, with $\sigma_{a}$ and $\sigma_{r}$ the 233 axial and radial stress, respectively; the deviatoric strain increment $\delta \varepsilon_{d}=2\left(\delta \varepsilon_{a}-\delta \varepsilon_{r}\right) / 3$ is a 234 function of the axial and radial strain increments; $\delta \varepsilon_{v}=\delta \varepsilon_{a}+2 \delta \varepsilon_{r}$ is the volumetric strain 235 increment; $K$ and $G$ are the bulk and shear moduli with the reference bulk and shear moduli $K_{0}$ and $236 G_{0}$; Poisson's ratio $v=\left(3 K_{0}-2 G_{0}\right) /\left(6 K_{0}+2 G_{0}\right)$; the non-linear elastic constant $n$ (typically 0.5 $2370.7) ; p_{a t}=101.325 \mathrm{kPa}$ is the atmospheric pressure chosen as the reference stress; $A_{d}$ and $d$ are the 238 stress-dilatancy parameters; $e_{c r 0}$ is the reference critical void ratio at extremely low confining 239 pressure; $\lambda$ and $\xi$ are material constants controlling the non-linearity of the critical state line; $\phi_{c}$ is 240 the critical friction angle.

241 Since the fines content evolves during internal erosion, the constitutive model needs to consider such 242 internal soil mass evolution. According to Yin et al. $(2014 ; 2016), e_{c r 0}$ is a function of the evolutive 243 fines content $f_{c}$, in order to unify the mechanical behavior of a sand-silt mixture for different fines 244 contents: 
$e_{c r 0}=\left[e_{h c, c r 0}\left(1-f_{c}\right)+a f_{c}\right] \frac{1-\tanh \left[\zeta\left(f_{c}-f_{t h}\right)\right]}{2}+e_{h f, c r 0}\left(f_{c}+\frac{1-f_{c}}{\left(R_{d}\right)^{m}}\right) \frac{1+\tanh \left[\zeta\left(f_{c}-f_{t h}\right)\right]}{2}$

246 where $e_{h c, c r 0}$ and $e_{h f, c r 0}$ are the reference critical void ratios for the pure sand and the pure silt,

247 respectively. $a, \zeta, R_{d}, m$ and $f_{t h}$ are material constants: $a$ controls the slope of the curve $e_{c r 0}-f_{c}$

248 for the silty sand varying from -1.0 to $1.0 . \mathrm{m}$ controls the slope of the curve $e_{c r 0}-f_{c}$ for the sandy

249 silt varying from 0.0 to $1.0, f_{\text {th }}$ and $\zeta$ control the transition zone between the silty sand and the

250 sandy silt. $\zeta$ controls the evolution rate of the transition zone $(\zeta=20$ after Yin et al. 2014; 2016),

$251 f_{t h}$ is the threshold fines content from a coarse grain skeleton to a fine grain skeleton, varying

252 usually from 0.2 to 0.35 on the basis of existing experimental data; $R_{d}$ is the ratio of the mean size of

253 the coarse grains $D_{50}$ to the mean size of the fine grains $d_{50}$. The material constants $a, m$ and $f_{t h}$ can

254 be determined by measuring the evolution of the minimum void ratio $e_{\min }$ versus $f_{c}$, which is

255 obtainable at low experimental cost, as suggested by Yin et al. (2014; 2016). It should be pointed out

256 that Eq. (22) is mathematically structured based on the hyperbolic tangent function to ensure a 257 continuous and smooth transition domain; more validation and discussion can be found in Yin et al. $258(2014 ; 2016)$

\section{2.6. Hydro-mechanical responses of soils during internal erosion}

260 Two main influences can be noted concerning the mechanical impact of the decrease of the fines 261 content induced by internal erosion. First, according to Eq.(18), the increase of the void ratio can 262 reduce the elastic moduli $G$ and $K$, leading to increasing deformation of the granular assembly. The 263 second consequence is linked to the interlocking features. The sliding resistance between particles 264 has two origins: one is the friction between two particles, the other is related to the geometrical 265 (topological) effect of the neighboring particles which will resist the sliding displacement of two 
266 particles in contact, i.e. the interlocking effect. From a macroscopic standpoint, the first aspect is

267 characterized by the internal friction angle $\phi_{c}$, corresponding to the critical state; the second aspect is 268 related to the density state, which will in turn influence the peak strength and the dilative/contractive 269 behavior of the soil. In the model, this interlocking influence is taken into account by Eqs. (20)-(22), 270 which relate the sliding resistance, controlled by the mobilized peak friction angle $\phi_{p}$ to the density 271 state $\left(e_{c} / e\right)$ of the assembly. Therefore, the loss of fine particles affects the interlocking, i.e. the 272 density state, by changing simultaneously the void ratio $e$ and the critical void ratio $e_{c}$. When a part 273 of the fine particles is detached from the soil skeleton, the void ratio $e$ increases, the critical void 274 ratio $e_{c}$ evolves according to the fines content $f_{c}$ evaluated by Eqs. (21)-(22). According to Yin et al. $275(2014,2016)$, in the case of a fine grain skeleton, the loss of fine particles will decrease the critical 276 void ratio $e_{c}$. From a microscopic standpoint, the loss of fine particles makes it easier for the force 277 chains which control the soil stability to buckle. As observed by Chang and Zhang (2011), the 278 dilative behavior of the non-eroded specimen changed to a contractive behavior after erosion. In the 279 case of a coarse grain skeleton, the loss of fine particles will make the critical state line move 280 upwards in the $e-\log p^{\prime}$ plane. The interlocking effect could, therefore, be enhanced when $e_{c} / e$ 281 increases. This might explain the observed increase of the initial peak strength of the eroded 282 specimen in some cases (e.g. Mehdizadeh et al. 2017). Thus, when a part of the fine particles is 283 detached from the soil skeleton, the void ratio $e$ increases, and the critical void ratio $e_{c}$ evolves 284 according to the fines content $f_{c}$, creating a disequilibrium of internal and external forces and, 285 consequently, a deformation of the granular assembly.

286 During an internal erosion experimental test, the soil specimen is subjected to constant boundary 287 stresses, whereas the amount of eroded fine particles increases progressively. Therefore, the stress 288 ratio $\eta$ is kept constant while the peak strength ratio $M_{p}$ and the initial stiffness $G_{\eta}$ evolve as a 
289 function of the density state of the soil. The shear strain can be written in an incremental form from 290 Eq. (15):

$$
\delta \varepsilon_{d}=-\frac{M_{p}^{(i)}}{G_{\eta}^{(i)}} \ln \left(1-\frac{\eta^{(i)}}{M_{p}^{(i)}}\right)+\frac{M_{p}^{(i-1)}}{G_{\eta}^{(i-1)}} \ln \left(1-\frac{\eta^{(i-1)}}{M_{p}^{(i-1)}}\right)
$$

292 with the superscript $(i)$ representing the current loading step and $(i-1)$ the previous loading step.

293 The volumetric strain increment can then be computed as:

$$
\delta \varepsilon_{v}=-\frac{p^{\prime}}{K^{2}} \delta K+A_{d}\left(M_{p t}-\frac{q}{p^{\prime}}\right) \delta \varepsilon_{d}[1-\exp (-d \eta)]
$$

295 The incremental modification of the void ratio induced by the body deformation is added to the void 296 ratio change caused by erosion:

$$
(\delta e)_{\mathrm{total}}=(\delta e)_{\mathrm{er}}+\delta \varepsilon_{v}(1+e)
$$

298 Under triaxial condition, the axial and radial strain increments $\left(\delta \varepsilon_{a}\right.$ and $\left.\delta \varepsilon_{r}\right)$ are functions of the shear and volumetric strain increments:

$$
\delta \varepsilon_{a}=\delta \varepsilon_{d}+\frac{1}{3} \delta \varepsilon_{v}, \quad \delta \varepsilon_{r}=\frac{1}{3} \delta \varepsilon_{v}-\frac{1}{2} \delta \varepsilon_{d}
$$

301 Thus, $\delta \varepsilon_{a}$ and $\delta \varepsilon_{r}$ can be used alternatively instead of $\delta \varepsilon_{d}$ and $\delta \varepsilon_{v}$.

302 The influence of the effective stress on the erosion of fine particles is considered in two parts. First, 303 the volume change induced by the effective stress $\left(\operatorname{div}\left(\mathbf{v}_{s}\right)=\partial\left(\varepsilon_{v}\right) / \partial t\right)$ has been used in the mass 304 balance equations (3)-(6). Thus, the impact of the effective stress is implied in the volume change, 305 which will further induce changes in the permeability as well as in the flow rate and the erosion rate, 306 according to Eqs. (10)-(14). Secondly, the mass exchange term $\hat{n}$ for the mass balance equations (3)- 
307 (6) is formulated to be dependent directly on the shear stress ratio $\eta / M_{p}$, according to Eqs. (13)-

308 (14), as shown by experimental results (e.g. Chang and Zhang 2011). However, the impact of the 309 confining pressure on the erodibility of fine particles still remains unclear since the results in the

310 literature (Chang and Zhang 2011, Bendahmane et al. 2008, Luo et al. 2013, and Ke and Takahashi

311 2014b, Moffat and Fannin 2011) present contradictions. More advanced experimental tests with

312 visualization of particles are needed to calibrate more precisely the relationship between the erosion 313 rate and the stress state.

\section{3 . Simulations of tests}

\section{3.1. Description of laboratory tests}

316 Chang and Zhang (2011) performed several hydraulic-gradient controlled downward erosion tests on 317 gap-graded HK-CDG mixtures with a newly developed stress-controlled erosion apparatus. These 318 experiments were performed in order to investigate the initiation and the development of internal 319 erosion in soils subjected to multi-step fluid flow under complex stress states, as well as the stress320 strain behavior of soils subjected to internal erosion. The experimental set-up consisted of a triaxial 321 apparatus, a pressurized water supply system, a particle collection system, and a water collection 322 system. A hollow base pedestal was designed for the eroded soil and the seepage water to pass 323 through in the downward direction. The tested soil was obtained by mixing the commercial washed 324 Leighton Buzzard sand (fraction E), and the completely decomposed granite (CDG) extracted from a 325 construction site on Beacon Hill, Hong Kong, following the grain size distribution shown in Figure 1.

326 Each triaxial specimen, $100 \mathrm{~mm}$ in diameter and $100 \mathrm{~mm}$ in high, was prepared by moist tamping to 327 prevent soil segregation. The erosion tests were carried out under initial isotropic and anisotropic 328 stresses with the major principal stress being parallel to the seepage direction. After a saturation 
329 stage, the consolidation of the specimen was realized by increasing gradually the confining stress.

330 For the tests under an anisotropic stress condition, the vertical stress was gradually increased up to

331 the target value after the specimen had been isotropically consolidated to a given stress state. After

332 the stress state being applied to the specimen, the pressurized water supply and the water collection

333 system were connected to the triaxial system. The hydraulic gradient, $i$, was increased in stages to

334 the final value (i.e., 0.15 per $10 \min$ for $i \leq 1.0,0.25$ per $10 \min$ for $1.0<i<2.0$, and 0.50 per 10

$335 \min$ for $i \geq 2.0$ ). For $10 \mathrm{~min}$, the hydraulic gradient was increased within the first 2 min and then

336 kept constant for the following $8 \mathrm{~min}$. Once the soil erosion was initiated, the hydraulic gradient was

337 kept constant until no further soil loss was observed (i.e. $<25.0 \mathrm{~g} / \mathrm{m}^{2}$ per $10 \mathrm{~min}$ ). Then, the hydraulic

338 gradient was increased to another level. A typical increase of the hydraulic gradient is illustrated in

339 Figure 2. During the internal erosion testing, the applied hydraulic gradient, the vertical displacement,

340 the outflow rate, and the eroded soil mass were continuously measured. The radial deformation was

341 deduced from planar deformation observed on digital photographs. Conventional drained triaxial

342 compression tests were then carried out to study the stress-strain behavior of the soil having been

343 subjected to internal erosion. Note that the samples of gap-graded or broadly graded granular soils

344 are normally more or less heterogeneous with non-uniform distribution of initial void ratio and fines

345 content in spatial space. During the erosion process, fluidized fine particles may be blocked when

346 passing the interface between the local "loose" area and the local "dense" area, which results in

347 heterogeneous particle size distributions. However, not enough detail (i.e. the evolution of pore

348 pressure along the height of the specimen) was given by Chang and Zhang (2011) to be able to

349 consider the initial heterogeneity of the soil specimen; as a consequence, the specimens in the

350 following simulations were assumed to be initially homogeneous.

351 A series of tests on the gap-graded HK-CDG mixtures samples (Chang 2012; Chang and Zhang 2011)

352 were selected for simulations. BM-C-1, BM-C-2, and BM-C-3 were conventional drained triaxial

353 tests on isotropically consolidated samples without erosion, under confining stresses of 50, 100, and 
$354200 \mathrm{kPa}$, respectively. GS-C-1, GS-C-2, and GS-C-3 were erosion tests under isotropic stress states 355 with confining stress of 50,100 and $200 \mathrm{kPa}$, respectively. GS-C-4, GS-C-5 and GS-C-6 were 356 erosion tests under anisotropic stress states with confining stress of $50 \mathrm{kPa}$ and deviatoric stress of 50 , $357100 \mathrm{kPa}$ and $150 \mathrm{kPa}$, respectively. For the eroded samples, drained triaxial tests were carried out 358 starting at the stress state applied during the erosion tests. More details about the laboratory test soil 359 can be found in (Chang 2012).

\section{3.2. Simulation schemes}

361 The numerical modeling scheme can be summarized in Figure 3 for granular media under constant 362 stresses considering internal erosion. $(i)$ represents the current step and $(i-1)$ the previous step. The 363 set of partial differential equations were solved explicitly in time and by the finite difference method 364 in space, the primary unknowns being the soil skeleton displacement $\left(\mathbf{u}_{s}(x, t)\right)$, the pore pressure ( $\left.365 p_{w}(x, t)\right)$, the porosity $(\phi(x, t))$, the fines content $\left(f_{c}(x, t)\right)$ and the concentration of fluidized 366 particles $(c(x, t))$. Other unknowns, such as the total discharge rate $\mathbf{q}_{w}(x, t)$, the density of the 367 mixture $\bar{\rho}(x, t)$, and the intrinsic permeability $k(x, t)$ could be explicitly determined by Eqs. (1) and 368 (10)-(12). For clarity, time $t$ and space $x$ variables are omitted in the equations.

369 Based on the above numerical scheme, the simulation could be conducted with the real dimensions 370 of the tests by using the finite element method to investigate the temporal and spatial variations of 371 the fines content and hydraulic conductivity during internal erosion. However, under the framework 372 of continuum mechanics, the erosion process is uniform under the assumption of an initially uniform 373 homogeneous specimen. In this study, the example of a well-controlled erosion coupled with the 374 mechanical loading triaxial tests on reconstructed specimens can be seen as a case of a representative 375 elementary volume with the hydraulic gradient across the specimen as input boundary condition. 
376 Hence, a very interesting simplified erosion and mechanics coupled simulation model can be 377 formulated, which should be useful in evaluating the eroded mass as well as the induced deformation 378 of the soil element. In conventional drained triaxial test simulations before and after erosion, the 379 confining stress was maintained constant. Thus, the ratio between the incremental deviatoric stress 380 and the incremental mean effective stress was equal to 3. From Eqs. (16) and (17), the deviatoric 381 stress and the volumetric strain could be obtained by imposing an incremental deviatoric strain as 382 follows:

$$
\delta q=3 G \delta \varepsilon_{d}\left(1-\frac{q}{p^{\prime} M_{p}}\right) /\left(1-\frac{q}{3 p^{\prime}}\right)
$$

$$
\delta p^{\prime}=\frac{\delta q}{3}
$$

$$
\delta \varepsilon_{v}=\frac{\delta p^{\prime}}{K}+A_{d}\left(M_{p t}-\frac{q}{p^{\prime}}\right) \delta \varepsilon_{d}[1-\exp (-d \eta)]
$$

386 Note that the above conventional drained triaxial test simulations were performed on a representative

387 elementary volume, thus the time $t$ and the space $x$ were not considered in the simulations.

\subsection{Calibration of parameters}

389 The physical properties of the soil mixtures are summarized in Table 1 . The initial void ratio $e_{0}$ 390 before the external stress being applied is 0.53 . The mechanical parameters were calibrated as 391 follows (see Figure 4): (a) the elastic parameters $\left(K_{0}, G_{0}\right.$ and $\left.n\right)$ were determined from an isotropic 392 compression test with an assumed value of Poisson's ratio $v=0.35$; (b) the friction angle $\phi_{c}$ was 393 determined from the stress paths of the triaxial tests; (c) the CSL related parameters $(\lambda, \xi)$ were 394 measured from drained triaxial tests. It was difficult to determine these two parameters because 
395 strain localizations appeared systematically at the end of the tests (Chang 2012); due to a lack of 396 experimental data, the assumption of parallel critical state lines was made, and the values suggested 397 by Yin et al. (2014) were adopted. (d) due to the lack of data concerning Chang's tests, the values of 398 the other parameters $\left(e_{h c, c r 0}, e_{h f, c r 0}, a, m\right.$ and $\left.f_{t h}\right)$ were assumed based on published data on other 399 similar materials (Yin et al. 2014; Yin et al. 2016); $e_{c r 0}$ was measured from experiments ( Figure 4 400 (b)); (e) finally, the dilatancy parameters ( $d$ and $A_{d}$ ) were determined by fitting the stress-strain 401 relations obtained in the triaxial tests BM-C-1, BM-C-2, and BM-C-3. The erosion parameters were 402 calibrated by fitting the time evolution of the hydraulic conductivity and the cumulative loss of dry 403 mass in tests GS-C-1 and GS-C-5. All determined parameters summarized in Table 2 and Table 3 404 were used to predict the hydro-mechanical behavior during the erosion tests and the following 405 drained triaxial tests after erosion. Note that the parameters can also be identified by using 406 optimization methods (Jin et al. 2018; Yin et al. 2017; Yin et al. 2018b).

407 Figure 5 shows the cumulative eroded soil mass and the variations in hydraulic conductivity during 408 the internal erosion tests under different stress states. The experimental results show that the stress 409 state during internal erosion affects significantly the hydraulic behavior of the soil. Specimens GS-C410 1, GS-C-5, and GS-C-6 were tested under the same confining pressure (50 kPa), but with different 411 deviatoric stresses: $0 \mathrm{kPa}, 100 \mathrm{kPa}$ and $150 \mathrm{kPa}$, respectively. Figure 5(a) shows the cumulative 412 weights of the eroded soil in the three tests. It was found that the average erosion rate within the 413 testing period increased with the increase of the deviatoric stress. Chang and Zhang (2011) attributed 414 this observation to the fact that the primary structure formed by the coarse particles became more 415 unstable with the increase of the applied stress ratio. Combined with the effect of the loss of fine 416 particles that provided lateral "support" for the primary soil skeleton structure, the erosion rate in the 417 highest stress ratio case (specimen GS-C-6) was much larger than that in the isotropic stress case 418 (specimen GS-C-1). Moreover, due to the loss of fine particles, the permeability increased 
419 significantly in the three tests as shown in Figure 5(b). The more the fine particles were lost, the

420 larger the permeability became. Finally, the permeability reached a relatively constant value.

421 The proposed model was able to reproduce the general trend of the erosion evolution until a stable

422 step was reached. However, some differences between experimental and numerical results could be

423 found, especially for the evolution of the hydraulic conductivity. After the loss of a significant

424 amount of fine particles, the soil specimen reached a new equilibrium state, where the increment of

425 the eroded mass was generally limited. During this period, the soil permeability slightly decreased

426 because part of the transported fine particles was assumed to be captured within the soil skeleton

427 during the erosion process, which induced a clogging of the constrictions among the coarse particles,

428 i.e. a self-filtration phenomenon. The decreased diameters of the effective pore throats resulted in a

429 reduction of permeability. Only few data are available in the literature concerning the self-filtration

430 phenomenon during an erosion test. Ke and Takahashi (2014a, 2014b) attributed the deviation of the

431 hydraulic conductivity to the difference in homogeneity along the reconstituted soil specimens,

432 induced probably by the segregation during preparation and placement of the specimen. Another

433 aspect which was not taken into account was the unknown influence of the saturation stage, which

434 might also lead to the heterogeneity of the soil sample before erosion. Not enough detail on this

435 particular aspect was given by Chang (2012) to calibrate the filtration term in the mass exchange

436 equations.

437 Figure 6 presents the applied increasing hydraulic gradients for the three internal erosion simulations 438 under different stress states. When the hydraulic gradient is increased to 0.6, i.e. the initiating 439 hydraulic gradient $i_{\text {start }}$, the fine particles will start to be eroded, as shown in Figure 5. According to 440 the above cited experimental tests of Chang and Zhang (2011), once the rate of the eroded weight 441 became smaller than $0.02 \mathrm{~g} / \mathrm{min}$, the hydraulic gradient was increased to another level. Sudden 442 increases in the erosion rate, hydraulic conductivity and deformations of the specimen were observed 
443 at a gradient of 1.5 , i.e. the soil skeleton deformation hydraulic gradient $i_{s d}$, as shown in Figures 5

444 and 7. In the numerical simulations, the final equilibrium states were reached at a gradient around 2.2

445 at $200 \mathrm{~min}$ for GS-C-1 and at $280 \mathrm{~min}$ for GS-C-5 and GS-C-6. Once the self-filtration mechanism is

446 added into the simulations, the critical hydraulic gradients could be expected to increase, and the

447 appearance of the final equilibrium state to be delayed. With the increase of the hydraulic gradient,

448 the pore channels previously clogged could be unblocked. This aspect will be discussed in future

449 work based on better documented experimental data that will consider the spatial variation of the fine

450 particles during internal erosion.

451 Figure 7 shows the axial and radial strains of the soil specimens caused by internal erosion. Here, the 452 negative values mean that the sample diameter increased. Larger axial and radial strains were 453 associated with higher stress ratios during the erosion process. The model was able to reproduce the 454 initial small deformation stage, the skeleton deformation stage and the final equilibrium stage. A 455 higher stress ratio was associated with larger axial and radial strains during the erosion process. 456 Moreover, from a macroscopic point of view, the jumps in the evolution of the specimen 457 deformation should be attributed to the changes in the hydraulic gradient. The results of the 458 simulations under the applied increasing hydraulic gradients during internal erosion shown in Figures 4596 and 7 demonstrate that the numerical approach is also able to reproduce the temporary equilibrium 460 state reached under the applied stresses with a relatively low hydraulic gradient.

\section{3.4. Mechanical responses after erosion}

462 Figure 8 illustrates a comparison between the experimental and the numerical results of drained 463 triaxial tests on samples before and after erosion. Both experimental and numerical results show that 464 the loss of fine particles during internal erosion affects significantly the mechanical behavior of the 465 soil. When the soil loses a significant number of fine particles, its stress-strain behavior changes 
466 from dilative to contractive. When a part of the solid fraction is eroded, the density state $\left(e_{c} / e\right)$

467 decreases and, as a consequence, the shear resistance decreases, creating additional deformation of 468 the granular assembly.

469 The proposed numerical approach was able to reproduce the general trend of the soil behavior up to 470 the peak strength which corresponded in the experiments to the development of strain localization 471 within the specimens. In some cases, discrepancies between experimental and numerical results 472 could be seen, possibly due to the difficulty of measuring accurately certain material properties, such 473 as the elastic stiffness or the friction angle, as a function of the fines content. Another aspect which 474 was not taken into account in the simulations was that heterogeneity within the specimen could be 475 produced by the combined effects of transport and filtration of the fine particles. Not enough detail 476 of this particular aspect was given by Chang (2012).

\section{4. Discussion}

478 Several numerical tests were performed on the HK-CDG samples to investigate systematically the 479 soil behavior which lost fines content during the erosion process, as well as the influences of soil's 480 initial density and initial fines content. After applying the external stresses, each specimen was 481 subjected to a hydraulic gradient at constant external stresses, as shown in Figure 2.

\section{4.1. Influence of the soil's initial state on the initiation of erosion}

483 According to Figures 5 and 6, the proposed model is able to distinguish the initiating hydraulic 484 gradient $i_{\text {start }}$ and the soil skeleton deformation hydraulic gradient $i_{s d}$ of the erosion process. 485 Numerical tests were performed on the HK-CDG samples to further study the influence of the soil's 486 initial state on the initiation of erosion. Figure 9 presents the cumulative weight of the eroded soil as 
487 a function of hydraulic gradient for (a) different initial fines contents and (b) different initial void 488 ratios. It is obvious that the increase of the initial fines content or the decrease of the initial void ratio 489 increases the hydraulic gradient required to cause erosion, which appears reasonable in view of the 490 experimental phenomenon.

\subsection{Effect of internal erosion on the hydro-mechanical response}

492 Numerical tests were performed on the HK-CDG samples, with $e_{0}=0.45$ and $f_{c 0}=0.35$. All the 493 specimens were isotropically consolidated up to $p^{\prime}=100 \mathrm{kPa}$ and then sheared at different stress 494 levels. Afterwards, each specimen was subjected to a hydraulic gradient while the external stresses 495 were kept constant. Figure 10 presents the axial and the volumetric strains versus the eroded fraction 496 of fine particles. For small stress ratios $\left(\eta=q / p^{\prime}<1\right)$, a slight contraction occurred with the increase 497 of the eroded fraction and the samples reached a final equilibrium state with an axial strain smaller 498 than $5 \%$ after the entire erosion process. For intermediate $\eta$ values $(\eta=1.0 ; 1.25)$, two stages could 499 be identified. Slight contractions occur firstly, and the axial strain developed slowly. After $20 \%$ and $50016.5 \%$ of the total mass being eroded for the samples under $\eta=1.0$ and 1.25 , the deformation 501 increased much faster and the samples exhibited a large contraction. This result indicates that, at this stage, important grain rearrangements occurred in the microstructure so as to reach a new stable mechanical state. However, for $\eta \geq 1.5$, no new equilibrium state could be reached; more details can

504 be found in the next section for similar numerical tests on denser samples. Obviously, given $\Delta f_{c}$ (or 505 the fines loss in terms of percentage of the total fines $\left.\Delta f_{c} / f_{c 0} \times 100 \%\right)$, values can be identified as the 506 triggering factor for the development of large macroscopic deformations. Furthermore, the higher the 507 stress ratio is during erosion, the smaller an eroded fraction will be needed in order to lead the 508 sample to failure. The predicted axial strains of GS-C-1 $(\eta=0)$, GS-C-5 $(\eta=1.2)$ and GS-C-6 $509 \quad(\eta=1.5)$ with large fines content loss are compared in Figure 11 (the solid lines correspond to loss 
510 of fines content observed in experiments, and the dashed lines predict the erosion evolution in case

511 the loss of fines content continues). It is shown that for the specimen GS-C-1 $(\eta=0)$, even if all the

512 fines are eroded, the deformation remains below 1\%; for specimens GS-C-5 $(\eta=1.2)$ and GS-C-6

$513(\eta=1.5)$, a temporary equilibrium state is reached at $\Delta f_{c}=5 \%$, and then remains stable up to $15 \%$

514 (for GS-C-6) and 18\% (for GS-C-5) of eroded fines. The axial strain then develops very rapidly with

515 a small loss of fines.

516 As presented in Figure 12(c) and Figure 12(f), the erosion process tends to increase the sample 517 porosity without producing significant macroscopic deformation, especially for low and medium $\eta$ 518 values. As shown by the DEM simulations in (Scholtès et al. 2010; Wood et al. 2008; Wood and 519 Maeda 2008), a certain amount of fine particles can be removed without significant consequence at 520 the macroscopic scale due to the presence of floating grains not involved in the force chain network. 521 Furthermore, the creation of a more open microstructure due to the loss of fines content dominates 522 the effect of sample compression induced by local destabilizations.

523 In order to bring all the specimens to failure, triaxial compression was performed on the samples 524 which stabilized after a certain fraction of the eroded mass. Figure 12 presents the simulations of the 525 erosion for different stress ratios $\eta=q / p^{\prime}$ and the following triaxial compression of the samples 526 which stabilized at $\Delta f_{c}=0.15$ and $\Delta f_{c}=0.25$, respectively. These results demonstrate that the 527 increase of the porosity produced a change in the specimen behavior from dilative to contractive. As 528 shown also in Figure 10, the strain path was linked to the stress ratio. It is remarkable that the 529 limiting threshold of $\eta$ under which the sample failed during erosion was generally smaller than the 530 value of $q / p^{\prime}$ at critical state $\left(\eta_{c s}\right)$ obtained from the drained triaxial tests and dependent on the amount of the loss of fines. For a high degree of erosion (i.e. $\Delta f_{c}=0.25$ as shown in Figure 12d-f), 532 the specimen developed large compaction during erosion, even though the stress ratio $\eta=1.0$ was far 
533 from its value at the critical state $\left(\eta_{c s}=1.68\right)$. Even if the soil became denser and, therefore,

534 somewhat stronger, large deformations might occur, leading to heavy damages to the earth structures.

535 As stated in (Hicher 2013), granular assemblies can develop instability at a shear stress level much

536 lower than the critical state failure line; the so-called diffuse failure can occur in highly eroded soils.

537 Besides, the results demonstrate that the proposed model was able to take into account the evolution

538 of the critical state which was different for the degraded specimens in comparison to the intact ones.

\section{4.3. Influence of the soil's initial density on the hydro-mechanical response}

540 Numerical tests were performed on dense samples of HK-CDG mixture, with $e_{0}=0.35$ and $541 f_{c 0}=0.35$, in order to evaluate the influence of the initial density of the soil on the mechanical 542 response during internal erosion. By comparing Figure 13 with Figure 10, it can be concluded that, at 543 a given stress ratio, a denser sample is more resistant and less inclined to deform when fine particles

544 are progressively eroded. A larger $\Delta f_{c}$ value is, therefore, necessary to trigger the development of 545 large macroscopic deformations. For high stress ratios $(\eta \geq 1.5)$, the specimens dilated with the loss 546 of fines. Let us consider the specimen with $\eta=1.6$ as an example. The volumetric and axial strains

547 of the specimen increased slowly to $0.2 \%$ and $1.4 \%$, respectively, until $\Delta f_{c}=12.5 \%$. Afterwards, the 548 volume of the specimen increased rapidly, indicating that the mechanical state of the soil changed 549 from stable to unstable, leading to the transition of the development of the axial strain from a slow to 550 a large increase. At $\Delta f_{c}=18.9 \%$, a sudden decrease of the volume indicated the failure of the 551 specimen, resulting in a high increase of the axial strain from $\varepsilon_{a}=5.9 \%$ to an unlimited value. The 552 final failure of the specimen was linked to the collapse of the initial microstructure, leading to the 553 rapid decrease of the specimen volume. 
554 Figure 14 presents the simulations of erosion for different stress ratios $\eta=q / p^{\prime}$ and the following 555 triaxial compression of the samples which stabilized at $\Delta f_{c}=0.15$ for (a-c) and $\Delta f_{c}=0.25$ for (d-f), 556 respectively. Compared to Figure 12, the results confirmed that, for initially denser specimens, the 557 initial microstructure supported more loss of fine particles with limited macroscopic deformation.

\section{4.4. Influence of the initial fines content on the hydro-mechanical response}

559 Natural soils can contain different proportions of fine particles. The influence of the initial fines 560 content on the mechanical behavior during erosion was evaluated by a series of numerical tests on 561 HK-CDG mixture with $e_{0}=0.45, f_{c 0}=0.2$. Figure 15 presents the specimen deformations in the 562 simulations of erosion for different stress ratios $\eta=q / p^{\prime}$ on HK-CDG mixture with $f_{c 0}=0.2$. By 563 comparing Figure 10 and Figure 15, it can be concluded that, for a low initial fines content, more 564 loss of fine particles is necessary to trigger large deformations. Let us consider the specimen with $565 \eta=1.65$ as an example. In the cases $f_{c 0}=0.35$ and 0.2 , respectively, the critical $\Delta f_{c}$ necessary to 566 trigger the failure are $1.5 \%$ and $15.5 \%$ respectively. This can be understood from the 567 phenomenological constitutive relation $f_{c}-e_{c r 0}$. The reference critical void ratio $e_{c r 0}$ corresponding 568 to the initial fines content $f_{c 0}$ is shown in Figure $4(\mathrm{~b})$. It can be seen that the value of $e_{c r 0}$ at $569 f_{c 0}=0.2$ is larger than that at $f_{c 0}=0.35$, leading to a higher initial position of the critical state line 570 in the $e-p^{\prime}$ plane. Therefore, the specimen with $f_{c 0}=0.2$ is in a denser state than the specimen 571 with $f_{c 0}=0.35$, evaluated by the value of $e_{0} / e_{c}$. This specimen remains stable until a large number 572 of fine particles are eroded. Nevertheless, the specimen under a large stress ratio exhibited a dilatant 573 behavior during the erosion process. 


\section{5. Conclusion}

575 This study provides a novel contribution to the numerical approach of quantifying the impact of 576 internal erosion on the mechanical behavior of granular soils. The detachment and transport of fine 577 particles induced by internal erosion has been modeled by a mass exchange between the solid and the 578 fluid phases. The governing equations were formulated based on the mass balance of four assumed 579 constituents: the stable fabric of the solid skeleton, the erodible fines, the fluidized particles, and the 580 fluid. A non-linear incremental model was adopted in order to obtain a non-linear stress-strain 581 relationship for the soil mixture. The model was enhanced by the introduction of the critical state 582 concept and by formulating the influence of the fines content on the critical state line in the $e-p$ ' 583 plane based on experimental results in order to take into account the impact of the amount of eroded 584 fines on soil deformability and strength.

585 An erosion and mechanics coupled model was formulated which is practical useful to evaluate the 586 eroded mass as well as deformation of soil specimen during internal erosion. This practical model 587 was used to simulate the behavior of HK-CDG mixtures before, during, and after erosion through 588 triaxial tests. After a significant amount of fine particle loss, the stress-strain behavior of the soil 589 changed from dilative to contractive with the shear resistance decreasing. The comparison between 590 experimental results and simulations demonstrated that the model can reproduce with a reasonable 591 success the initiation of internal erosion, the sudden increases in erosion rate, the change in hydraulic 592 conductivity and the deformations of the specimen. The results confirmed that the deformation was 593 linked to the stress ratio under which the erosion process was active. Note that it is in our interest to 594 understand better the development of internal erosion. The experimental analysis on erosion induced 595 deformations under controlled stress states is still in its infancy, not to mention the systematic 596 analysis of the influence of the soil's initial states (initial relative density and fines content) under 597 different stress states. Therefore, the influence of the stress state and the soil's initial states (relative 
598 density and fines content) were investigated from a numerical standpoint. Interestingly, besides the 599 stress ratio, the amount of loss of fines indicating the yielding from a stable to an unstable 600 mechanical response appeared to be related to the initial density as well as to the initial fines content 601 of the soil mixture. These results should provide some inspiration for the design of future 602 experiments in order to better understand the physics of internal erosion and its impact on the soil 603 behavior.

604 It is worth mentioning that this study does contain some limitations which could be remediated in 605 future work. The consideration of the self-filtration process and the initial heterogeneity of the 606 specimen might influence the critical hydraulic gradient and delay the final equilibrium state. More 607 advanced laboratory testing in a triaxial permeameter with well-documented data on the spatial 608 variations during internal erosion will be needed for the development, calibration, validation and 609 verification of the model.

\section{Acknowledgement}

611 The financial support provided by both the National Natural Science Foundation of China 612 (51579179) and the National Institute for Industrial Environment and Risks of France (INERIS) is 613 gratefully acknowledged.

\section{References}

615 Bendahmane, F., Marot, D., and Alexis, A. 2008. Experimental parametric study of suffusion and backward erosion. Journal of geotechnical and geoenvironmental engineering, 134(1): 57-67.

Bonelli, S., and Marot, D. On the modelling of internal soil erosion. In The 12th International Conference of International Association for Computer Methods and Advances in Geomechanics (IACMAG). 2008. p. 7.

Borja, R.I. 2006. On the mechanical energy and effective stress in saturated and unsaturated porous continua. International Journal of Solids and Structures, 43(6): 1764-1786.

Burenkova, V. 1993. Assessment of suffusion in non-cohesive and graded soils. Filters in geotechnical and hydraulic engineering. Balkema, Rotterdam: 357-360. 
Chang, D. 2012. Internal erosion and overtopping erosion of earth dams and landslide dams. The Hong Kong University of Science and Technology.

Chang, D., and Zhang, L. 2011. A stress-controlled erosion apparatus for studying internal erosion in soils. Geotechnical Testing Journal., 34(6): 579-589.

Cividini, A., and Gioda, G. 2004. Finite-element approach to the erosion and transport of fine particles in granular soils. International Journal of Geomechanics, 4(3): 191-198.

Cividini, A., Bonomi, S., Vignati, G.C., and Gioda, G. 2009. Seepage-induced erosion in granular soil and consequent settlements. International Journal of Geomechanics, 9(4): 187-194.

Crosta, G., and Prisco, C.d. 1999. On slope instability induced by seepage erosion. Canadian Geotechnical Journal, 36(6): 1056-1073.

de Boer, R. 2000. Contemporary progress in porous media theory. Applied Mechanics Reviews, 53(12): 323-370.

Fell, R., Wan, C.F., Cyganiewicz, J., and Foster, M. 2003. Time for development of internal erosion and piping in embankment dams. Journal of geotechnical and geoenvironmental engineering, 129(4): 307-314.

Foster, M., Fell, R., and Spannagle, M. 2000. The statistics of embankment dam failures and accidents. Canadian Geotechnical Journal, 37(5): 1000-1024.

Foster, M., and Fell, R. 2001. Assessing embankment dam filters that do not satisfy design criteria. Journal of geotechnical and geoenvironmental engineering, 127(5): 398-407.

Hicher, P.-Y. 2013. Modelling the impact of particle removal on granular material behaviour. Géotechnique, 63(2): 118.

Hosn, R.A., Sibille, L., Benahmed, N., and Chareyre, B. 2018. A discrete numerical model involving partial fluid-solid coupling to describe suffusion effects in soils. Computers and Geotechnics, 95: 30-39.

Hu, W., Hicher, P.-Y., Scaringi, G., Xu, Q., Van Asch, T., and Wang, G. 2018. Seismic precursor to instability induced by internal erosion in loose granular slopes. Géotechnique: 1-13.

Jin, Y.-F., Wu, Z.-X., Yin, Z.-Y., and Shen, J.S. 2017. Estimation of critical state-related formula in advanced constitutive modeling of granular material. Acta Geotechnica, 12(6): 1329-1351.

Jin, Y.-F., Yin, Z.-Y., Wu, Z.-X., and Zhou, W.-H. 2018. Identifying parameters of easily crushable sand and application to offshore pile driving. Ocean Engineering, 154: 416-429.

Jin, Y.F., Yin, Z.Y., Shen, S.L., and Hicher, P.Y. 2016. Selection of sand models and identification of parameters using an enhanced genetic algorithm. International journal for numerical and analytical methods in geomechanics, 40(8): 1219-1240.

Jin, Y.F., and Yin, Z.Y. 2018. ErosLab: A modelling tool for soil tests. Advances in Engineering Software, 121: 84-97.

Ke, L., and Takahashi, A. 2014a. Experimental investigations on suffusion characteristics and its mechanical consequences on saturated cohesionless soil. Soils and foundations, 54(4): 713730.

Ke, L., and Takahashi, A. 2014b. Triaxial erosion test for evaluation of mechanical consequences of internal erosion. Geotechnical Testing Journal, 37(2): 347-364.

Ke, L., and Takahashi, A. 2015. Drained monotonic responses of suffusional cohesionless soils. Journal of geotechnical and geoenvironmental engineering, 141(8): 04015033.

Ke, L., Ouyang, M., Horikoshi, K., and Takahashi, A. 2016. Soil deformation due to suffusion and its consequences on undrained behavior under various confining pressures. Japanese Geotechnical Society Special Publication, 2(8): 368-373.

Kenney, T., and Lau, D. 1985. Internal stability of granular filters. Canadian Geotechnical Journal, 22(2): 215-225.

Kenney, T., and Lau, D. 1986. Internal stability of granular filters: Reply. Canadian Geotechnical Journal, 23(3): 420-423.

Kézdi, A. 1979. Soil physics-selected topics-developments in geotechnical engineering- 25. 
Li, M., and Fannin, R.J. 2008. Comparison of two criteria for internal stability of granular soil. Canadian Geotechnical Journal, 45(9): 1303-1309.

Lominé, F., Scholtès, L., Sibille, L., and Poullain, P. 2013. Modeling of fluid-solid interaction in granular media with coupled lattice Boltzmann/discrete element methods: application to piping erosion. International journal for numerical and analytical methods in geomechanics, 37(6): 577-596.

Luo, Y., Qiao, L., Liu, X., Zhan, M., and Sheng, J. 2013. Hydro-mechanical experiments on suffusion under long-term large hydraulic heads. Natural Hazards, 65(3): 1361-1377.

Mansouri, M., El Youssoufi, M.S., and Nicot, F. 2017. Numerical simulation of the quicksand phenomenon by a 3D coupled Discrete Element - Lattice Boltzmann hydromechanical model. International journal for numerical and analytical methods in geomechanics, 41(3): 338-358.

Marot, D., Rochim, A., Nguyen, H.-H., Bendahmane, F., and Sibille, L. 2016. Assessing the susceptibility of gap-graded soils to internal erosion: proposition of a new experimental methodology. Natural Hazards, 83(1): 365-388.

Mehdizadeh, A., Disfani, M.M., Evans, R., and Arulrajah, A. 2017. Progressive internal erosion in a gap-graded internally unstable soil: mechanical and geometrical effects. International Journal of Geomechanics, 18(3): 04017160.

Moffat, R.A., and Fannin, R.J. 2006. A large permeameter for study of internal stability in cohesionless soils. Geotechnical Testing Journal, 29(4): 273-279.

Moffat, R.A., Fannin, R.J., and Garner, S.J. 2011. Spatial and temporal progression of internal erosion in cohesionless soil. Canadian Geotechnical Journal, 48(3): 399-412.

Muir Wood, D. 2007. The magic of sands-the 20th Bjerrum Lecture presented in Oslo, 25 November 2005. Canadian Geotechnical Journal, 44(11): 1329-1350.

Muir Wood, D., Maeda, K., and Nukudani, E. 2010. Modelling mechanical consequences of erosion. Géotechnique, 60(6): 447-457.

Papamichos, E., Vardoulakis, I., Tronvoll, J., and Skjaerstein, A. 2001. Volumetric sand production model and experiment. International journal for numerical and analytical methods in geomechanics, 25(8): 789-808.

Reboul, N. 2008. Transport de particules dans les milieux granulaires: Application à l'érosion interne. Ecully, Ecole centrale de Lyon.

Reddi, L.N., Lee, I.-M., and Bonala, M.V. 2000. Comparison of internal and surface erosion using flow pump tests on a sand-kaolinite mixture. Geotechnical Testing Journal, 23(1): 116-122.

Revil, A., and Cathles, L. 1999. Permeability of shaly sands. Water Resources Research, 35(3): 651662.

Rochim, A., Marot, D., Sibille, L., and Thao Le, V. 2017. Effects of Hydraulic Loading History on Suffusion Susceptibility of Cohesionless Soils. Journal of geotechnical and geoenvironmental engineering, 143(7): 04017025.

Rönnqvist, H., Fannin, J., and Viklander, P. 2014. On the use of empirical methods for assessment of filters in embankment dams. Géotechnique Letters, 4(4): 272-282.

Sari, H., Chareyre, B., Catalano, E., Philippe, P., and Vincens, E. Investigation of internal erosion processes using a coupled dem-fluid method. In Particles 2011 II International Conference on Particle-Based Methods, E. Oate and DRJ Owen (Eds), Barcelona. 2011. pp. 1-11.

Schaufler, A., Becker, C., and Steeb, H. 2013. Infiltration processes in cohesionless soils. ZAMM Journal of Applied Mathematics and Mechanics/Zeitschrift für Angewandte Mathematik und Mechanik, 93(2 - 3): 138-146.

Scholtès, L., Hicher, P.-Y., and Sibille, L. 2010. Multiscale approaches to describe mechanical responses induced by particle removal in granular materials. Comptes Rendus Mécanique, 338(10-11): 627-638. 
Sherard, J. Sinkholes in dams of coarse, broadly graded soils. 13th Int. In Congress on Large Dams, New Delhi Q. 1979. p. R2.

Sibille, L., Marot, D., and Sail, Y. 2015a. A description of internal erosion by suffusion and induced settlements on cohesionless granular matter. Acta Geotechnica, 10(6): 735-748.

Sibille, L., Lominé, F., Poullain, P., Sail, Y., and Marot, D. 2015b. Internal erosion in granular media: direct numerical simulations and energy interpretation. Hydrological Processes, 29(9): 2149-2163.

Skempton, A., and Brogan, J. 1994. Experiments on piping in sandy gravels. Géotechnique, 44(3): 449-460.

Slangen, P., and Fannin, R. 2016. A Flexible Wall Permeameter for Investigating Suffusion and Suffosion. Geotechnical Testing Journal, 40(1): 1-14.

Stavropoulou, M., Papanastasiou, P., and Vardoulakis, I. 1998. Coupled wellbore erosion and stability analysis. International journal for numerical and analytical methods in geomechanics, 22(9): 749-769.

Steeb, H., and Diebels, S. 2003. A thermodynamic-consistent model describing growth and remodeling phenomena. Computational materials science, 28(3): 597-607.

Sterpi, D. 2003. Effects of the erosion and transport of fine particles due to seepage flow. International Journal of Geomechanics, 3(1): 111-122.

Uzuoka, R., and Borja, R.I. 2012. Dynamics of unsaturated poroelastic solids at finite strain. International journal for numerical and analytical methods in geomechanics, 36(13): 15351573.

Uzuoka, R., Ichiyama, T., Mori, T., and Kazama, M. Hydro-mechanical analysis of internal erosion with mass exchange between solid and water. In 6th International Conference on Scour and Erosion. 2012. pp. 655-662.

Vardoulakis, I., Stavropoulou, M., and Papanastasiou, P. 1996. Hydro-mechanical aspects of the sand production problem. Transport in porous media, 22(2): 225-244.

Wan, C.F., and Fell, R. 2004. Investigation of rate of erosion of soils in embankment dams. Journal of geotechnical and geoenvironmental engineering, 130(4): 373-380.

Wan, C.F., and Fell, R. 2008. Assessing the potential of internal instability and suffusion in embankment dams and their foundations. Journal of geotechnical and geoenvironmental engineering, 134(3): 401-407.

Wood, D., Maeda, K., and NUKUDANI, E. 2008. c. In Fourth International Conference on Scour and Erosion. pp. 491-496.

Wood, D.M., and Maeda, K. 2008. Changing grading of soil: effect on critical states. Acta Geotechnica, 3(1): 3-14.

$\mathrm{Xu}$, Y., and Zhang, L. 2009. Breaching parameters for earth and rockfill dams. Journal of geotechnical and geoenvironmental engineering, 135(12): 1957-1970.

Yin, Z.-Y., Zhao, J., and Hicher, P.-Y. 2014. A micromechanics-based model for sand-silt mixtures. International Journal of Solids and Structures, 51(6): 1350-1363.

Yin, Z.-Y., Huang, H.-W., and Hicher, P.-Y. 2016. Elastoplastic modeling of sand-silt mixtures. Soils and foundations, 56(3): 520-532.

Yin, Z.-Y., Wu, Z.-X., and Hicher, P.-Y. 2018a. Modeling Monotonic and Cyclic Behavior of Granular Materials by Exponential Constitutive Function. Journal of Engineering Mechanics, 144(4): 04018014.

Yin, Z.-Y., Jin, Y.-F., Shen, S.-L., and Huang, H.-W. 2017. An efficient optimization method for identifying parameters of soft structured clay by an enhanced genetic algorithm and elasticviscoplastic model. Acta Geotechnica, 12(4): 849-867.

Yin, Z.Y., Jin, Y.F., Shen, J.S., and Hicher, P.Y. 2018b. Optimization techniques for identifying soil parameters in geotechnical engineering: Comparative study and enhancement. International journal for numerical and analytical methods in geomechanics, 42(1): 70-94. 
773 Zhang, F., Li, M., Peng, M., Chen, C., and Zhang, L. 2018. Three-dimensional DEM modeling of the stress-strain behavior for the gap-graded soils subjected to internal erosion. Acta Geotechnica: 1-17.

Zhang, L., and Chen, Q. 2006. Seepage failure mechanism of the Gouhou rockfill dam during reservoir water infiltration. Soils and foundations, 46(5): 557-568.

Zhang, L., and Du, J. 1997. Effects of abutment slopes on the performance of high rockfill dams. Canadian Geotechnical Journal, 34(4): 489-497.

Zhang, L., Xu, Y., and Jia, J. 2009. Analysis of earth dam failures: A database approach. Georisk, 3(3): 184-189.

Zhang, X., Wong, H., Leo, C., Bui, T., Wang, J., Sun, W., and Huang, Z. 2013. A thermodynamicsbased model on the internal erosion of earth structures. Geotechnical and Geological Engineering, 31(2): 479-492.

Zhao, J., and Shan, T. 2013. Coupled CFD-DEM simulation of fluid-particle interaction in geomechanics. Powder technology, 239: 248-258. 


\section{Figure captions}

789 Figure 1. Grain size distribution of the tested HK-CDG mixture

790 Figure 2. Illustration of increasing hydraulic gradient applied during internal erosion test

791 Figure 3. Computation flowchart for internal erosion under constant stresses

792 Figure 4. (a) Isotropic compression test simulation and critical state; (b) fitted reference critical void

793 ratio versus fines content for HK CDG mixture

794 Figure 5. Comparison between experimental results and simulations for HK CDG mixture during 795 erosion tests under different stress states: (a) Cumulative eroded soil mass and (b) variations of the 796 coefficient of permeability

797 Figure 6. Increasing hydraulic gradients applied during internal erosion for simulations

798 Figure 7. Comparison of the deformation of the specimen between experimental results and 799 simulations for HK CDG mixture during erosion tests under different stress states: (a) axial strain 800 and (b) radial strain.

801 Figure 8. Comparison between experimental results and simulations for HK-CDG mixture before 802 and after erosion: (a,c) deviatoric stress versus axial strain; $(b, d)$ void ratio versus axial strain

803 Figure 9. Cumulative weight of eroded soil as a function of hydraulic gradient for (a) different initial 804 fines contents; and (b) different initial void ratios

805 Figure 10. Specimen deformations as a function of the eroded fraction of fine particles in the 806 simulations of erosion for different stress ratios $\eta=q / p^{\prime}$ : (a) axial strains; (b) volumetric strains 
808 Figure 12. Simulations of erosion for different stress ratio $\eta=q / p^{\prime}$ and the following triaxial 809 compression which stabilized at $\Delta f_{c}=0.15$ for $(\mathrm{a}-\mathrm{c})$, and $\Delta f_{c}=0.25$ for $(\mathrm{d}-\mathrm{f})$, respectively: the 810 thick blue lines indicate the triaxial compression of the initial specimen, the dashed thin lines 811 indicate the erosion process, the solid lines indicate the following triaxial compression of the eroded 812 samples

813 Figure 13. Specimen deformations in the simulations of erosion for different stress ratio $\eta=q / p^{\prime}$ on 814 dense HK-CDG mixture with $e_{0}=0.35$ : (a) axial strains and (b) volumetric strains as a function of 815 eroded fraction of fine particles.

816 Figure 14. Simulations of erosion on initially dense HK-CDG mixture with $e_{0}=0.35$ for different 817 stress ratio $\eta=q / p^{\prime}$ and the following triaxial compression which stabilized at $\Delta f_{c}=0.15$ for (a-c), 818 and $\Delta f_{c}=0.25$ for $(\mathrm{d}-\mathrm{f})$ respectively: thick blue lines indicate the triaxial compression of the initial 819 specimen, dashed thin lines indicate the erosion process, solid lines indicate the triaxial compression 820 of the eroded samples

821 Figure 15. Specimen deformations in the simulations of erosion for different stress ratios $\eta=q / p^{\prime}$ on 822 sand mixture with $f_{c 0}=0.2:(\mathrm{a}, \mathrm{b})$ axial and volumetric strains as a function of the eroded fraction of 823 fine particles; (c,d) porosity and volumetric strain as a function of axial strain. 


\section{Appendix A1. Four-constituent continuum model}

2 In a given Representative Elementary Volume (REV), $\mathrm{d} V$ consisting of the four constituents, the

3 volume fraction of a single constituent $x$ is expressed as:

$$
n^{i}(x, t)=\frac{\mathrm{d} V^{i}(x, t)}{\mathrm{d} V}
$$

5 with $i=\{s s, s e, f f, f p\}$ denoting the 4 constituents: the stable fabric of the solid skeleton, the erodible

6 fines, the fluidized particles and the pure fluid phase; $d V^{x}$ denoting the volume of the corresponding

7 constituent.

8 At a material point level, the mass balance for the $i$ phase is given, neglecting the hydro-mechanical 9 dispersion tensor, by Schaufler et al. (2013):

$$
\frac{\partial\left(\rho^{i}\right)}{\partial t}+\operatorname{div}\left(\rho^{i} \mathbf{v}^{i}\right)=\rho^{e x, i}
$$

11 where $\rho^{e x, i}$ and $\mathbf{v}^{i}$ denote, respectively, the mass exchange term and the velocity of the

12 corresponding constituent. The mass balances for the four constituents can be reduced to the

13 corresponding volume balance:

$$
\frac{\partial\left(n^{i}\right)}{\partial t}+\operatorname{div}\left(n^{i} \mathbf{v}^{i}\right)=n^{e x, i}
$$

$15 n^{e x, x}$ is the term of the volume of mass exchange.

16 The porosity field $\phi(x, t)$, the amount of erodible fines $f_{c}(x, t)$ and the concentration of the

17 fluidized particles $c(x, t)$ are defined as follows: 


$$
\phi=n^{f f}+n^{f p}, f_{c}=\frac{n^{s e}}{1-\phi}, c=\frac{n^{f p}}{\phi}
$$

19 The phase transition of the fine particles from solid to fluidized particles leads to:

20

$$
-n^{e x, f p}=n^{e x, s e}=\hat{n}, n^{e x, s s}=0, n^{e x, f f}=0
$$

21 The mass balance equations are then given by Eqs. (3)-(6). 


\section{Tables}

Table 1 Physical properties of the tested soil mixtures

\begin{tabular}{|l|l|l|}
\hline Density of fluid & $\rho_{f}$ & $1.00 \mathrm{~g} / \mathrm{cm}^{3}$ \\
\hline Density of solids & $\rho_{s}$ & $2.65 \mathrm{~g} / \mathrm{cm}^{3}$ \\
\hline Kinematic viscosity of fluid & $\eta_{k}$ & $5.0 \times 10^{-6} \mathrm{~m}^{2} \cdot \mathrm{s}^{-1}$ \\
\hline Initial porosity & $\phi_{0}$ & 0.34 \\
\hline Initial permeability & $k$ & $7.5 \times 10^{-5} \mathrm{~m} \cdot \mathrm{s}^{-1}$ \\
\hline Initial fines content & $f_{c 0}$ & 0.35 \\
\hline
\end{tabular}

3

4

Table 2. Mechanical constants of HK-CDG mixture

\begin{tabular}{|c|c|c|c|c|c|c|c|c|c|}
\hline \multicolumn{3}{|c|}{$\begin{array}{c}\text { Elastic } \\
\text { parameters }\end{array}$} & \multicolumn{2}{|c|}{$\begin{array}{c}\text { Dilatancy } \\
\text { parameters }\end{array}$} & \multicolumn{5}{|c|}{$\begin{array}{l}\text { CSL-related } \\
\text { parameters }\end{array}$} \\
\hline $\begin{array}{c}K_{0} / M P a \\
50\end{array}$ & $\begin{array}{c}G_{0} / M P a \\
167\end{array}$ & $\begin{array}{c}n \\
0.95\end{array}$ & $\begin{array}{c}d \\
18\end{array}$ & $\begin{array}{c}A_{d} \\
0.35\end{array}$ & $\begin{array}{c}e_{h c, c r 0} \\
08\end{array}$ & $\begin{array}{l}e_{f c, c r 0} \\
0.86\end{array}$ & $\begin{array}{c}\xi \\
0.45\end{array}$ & $\begin{array}{c}\lambda \\
0.03\end{array}$ & $\begin{array}{c}\phi_{c} \\
40.5\end{array}$ \\
\hline
\end{tabular}

5

Table 3. Erosion constants of HK-CDG mixture

\begin{tabular}{|c|c|c|c|c|c|c|c|}
\hline \multicolumn{3}{|c|}{$\begin{array}{c}\text { Fines } \\
\text { parameters }\end{array}$} & \multicolumn{5}{|c|}{$\begin{array}{c}\text { Erosion } \\
\text { parameters }\end{array}$} \\
\hline$a$ & $m$ & $\overline{f_{t h}}$ & $\lambda_{e}$ & $\alpha_{1}$ & $\alpha_{2}$ & $\alpha_{3}$ & $m_{k}$ \\
\hline 0.79 & 0.46 & 0.28 & 1 & 0.8 & 2.7 & 0.05 & 4 \\
\hline
\end{tabular}




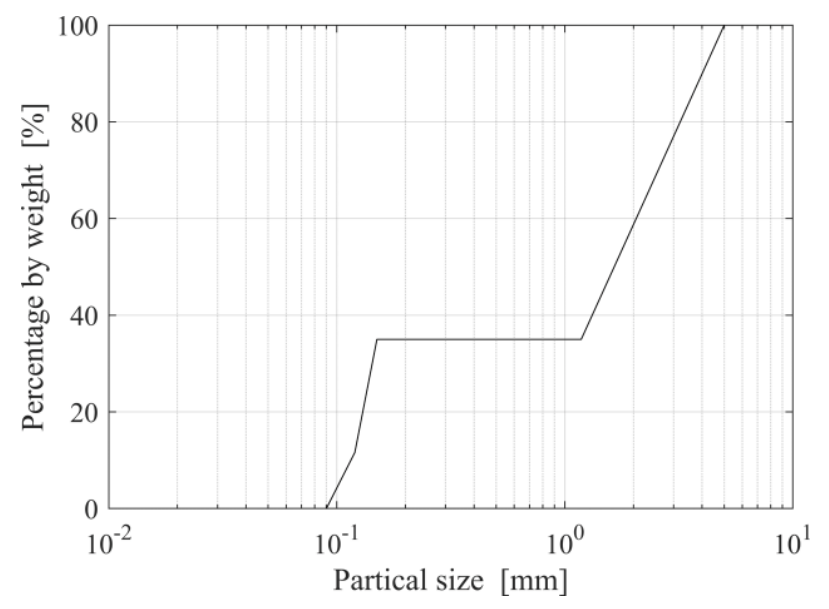

Figure 1. Grain size distribution of the tested HK-CDG mixture 


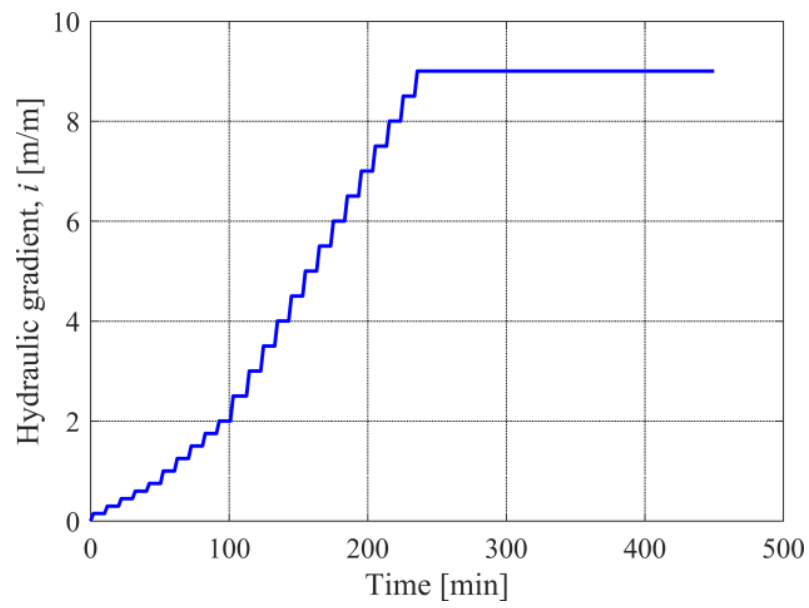

Figure 2. Illustration of increasing hydraulic gradient applied during internal erosion test 


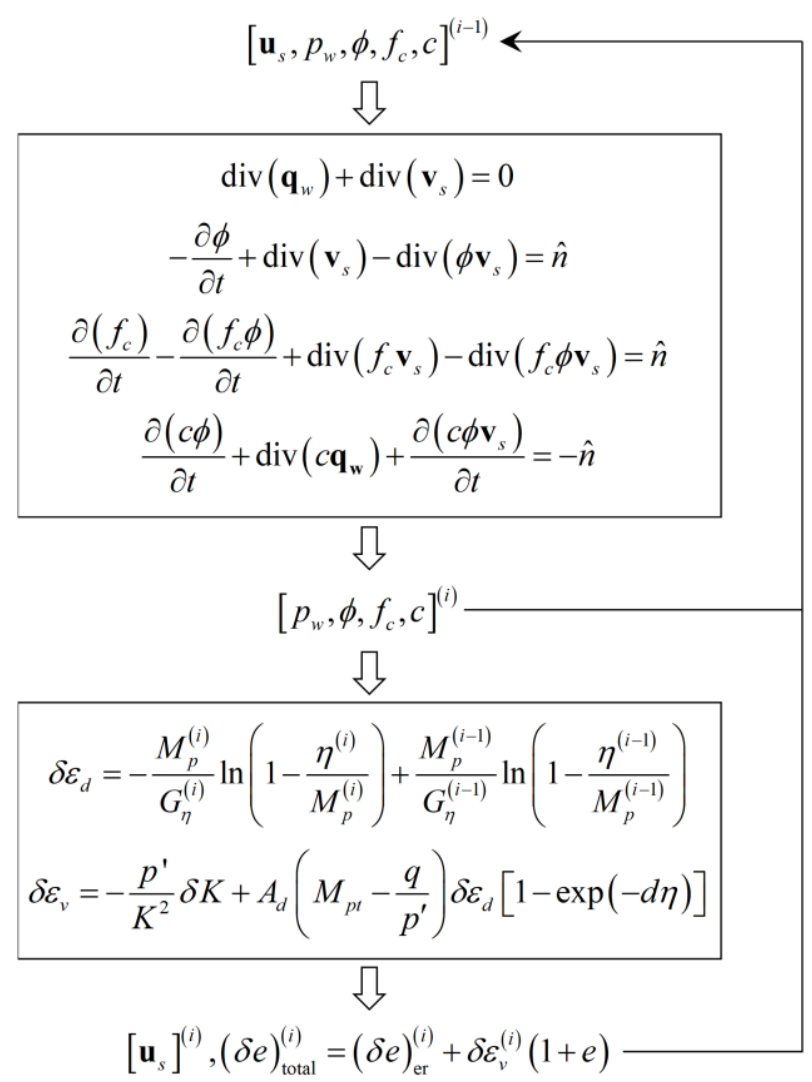

Figure 3. Computation flowchart for internal erosion under constant stresses 

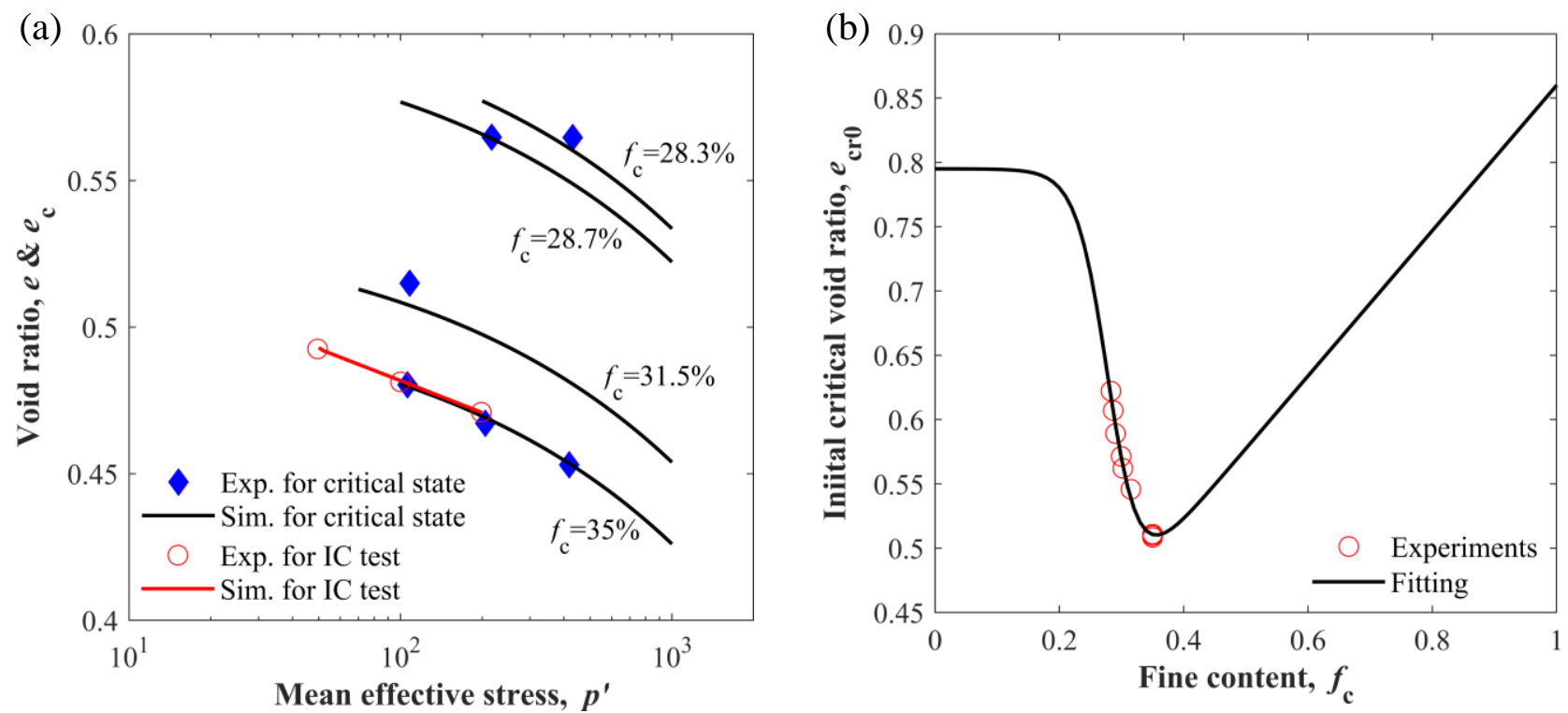

Figure 4. (a) Isotropic compression test simulation and critical state; (b) fitted reference critical void ratio versus fines content for HK CDG mixture 
(a)

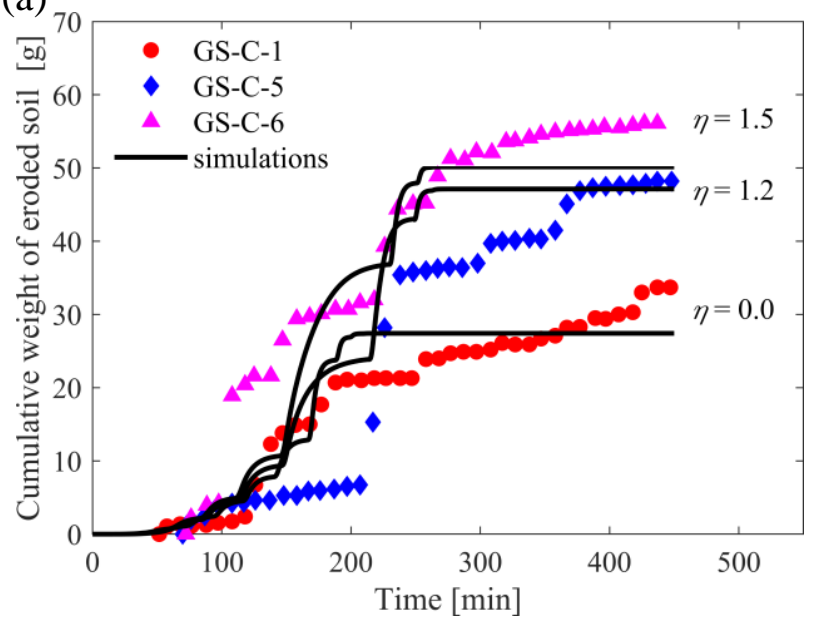

(b)

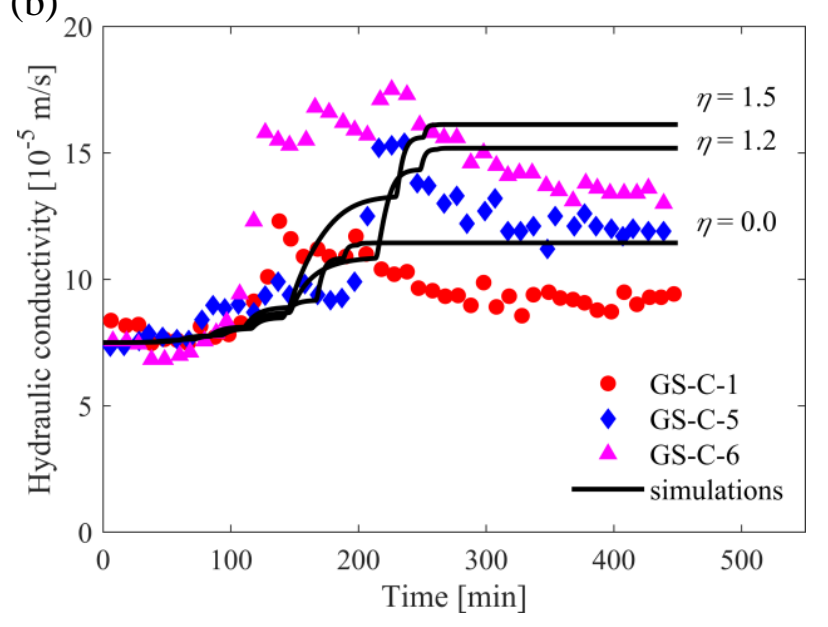

Figure 5. Comparison between experimental results and simulations for HK CDG mixture during erosion tests under different stress states: (a) Cumulative eroded soil mass and (b) variations of the coefficient of permeability 


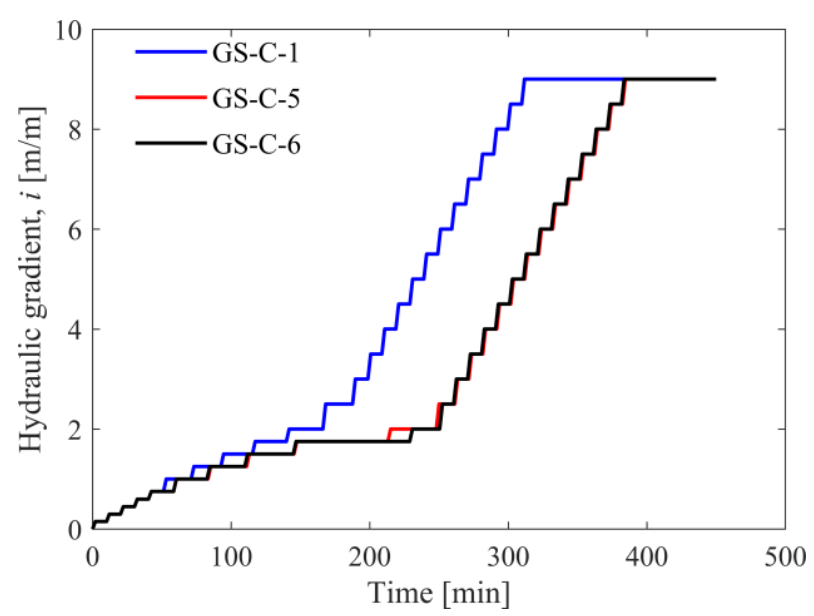

Figure 6. Increasing hydraulic gradients applied during internal erosion for simulations 

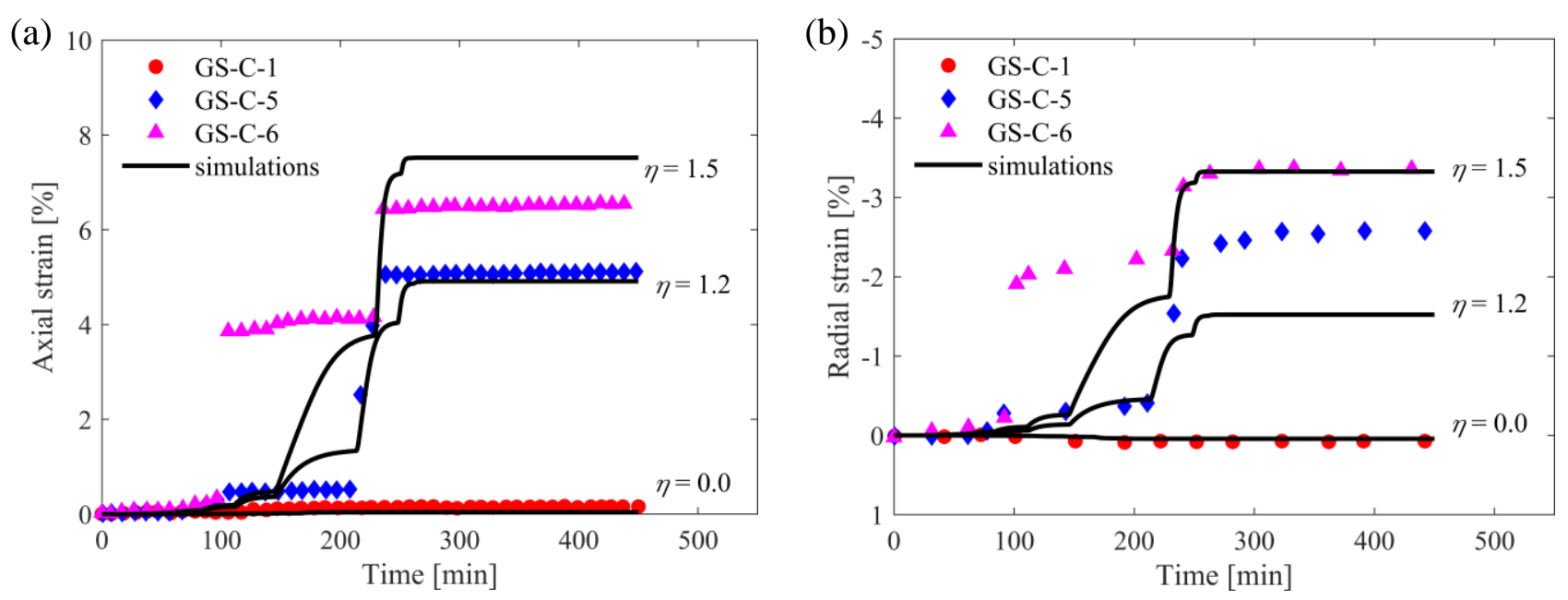

Figure 7. Comparison of the deformation of the specimen between experimental results and simulations for HK CDG mixture during erosion tests under different stress states:

(a) axial strain and (b) radial strain. 

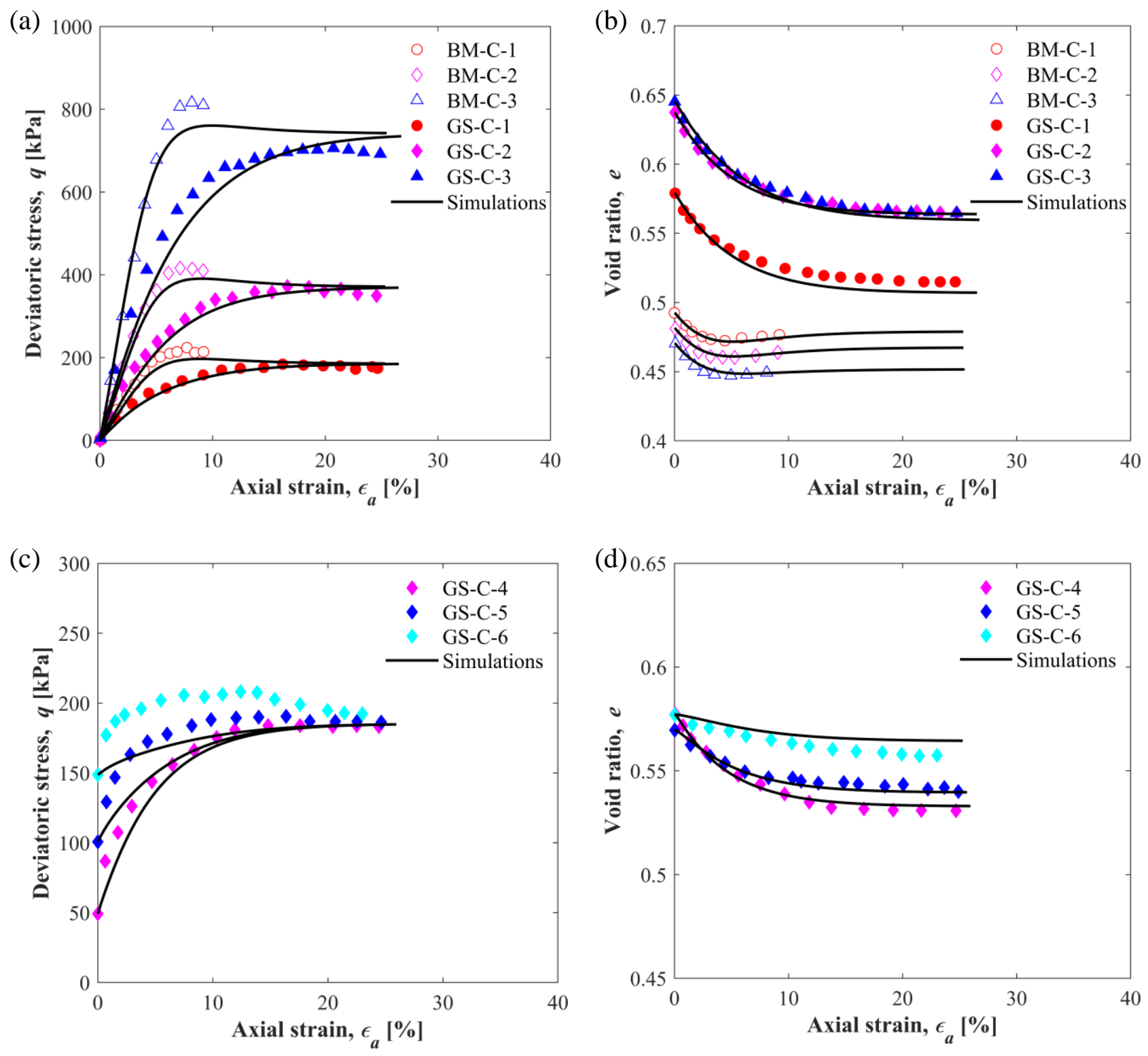

Figure 8. Comparison between experimental results and simulations for HK-CDG mixture before and after erosion: (a,c) deviatoric stress versus axial strain; $(b, d)$ void ratio versus axial strain 

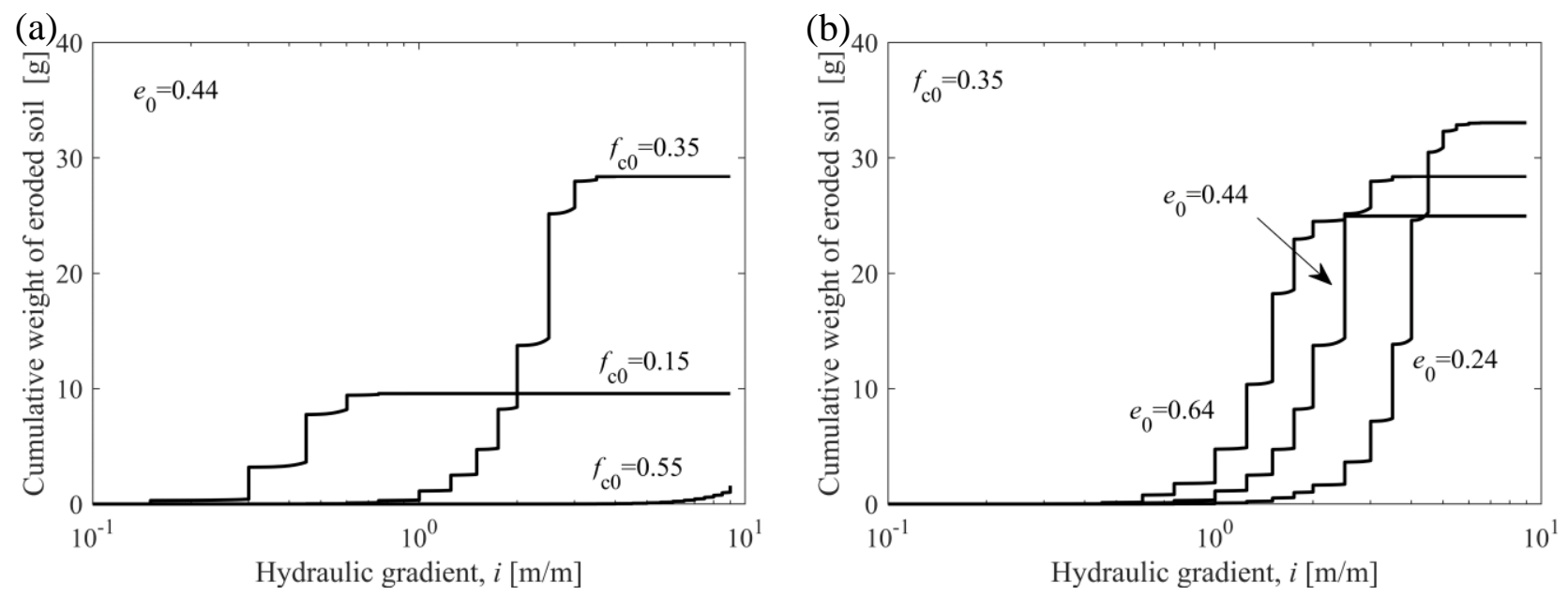

Figure 9. Cumulative weight of eroded soil as a function of hydraulic gradient for (a) different initial fines contents; and (b) different initial void ratios 

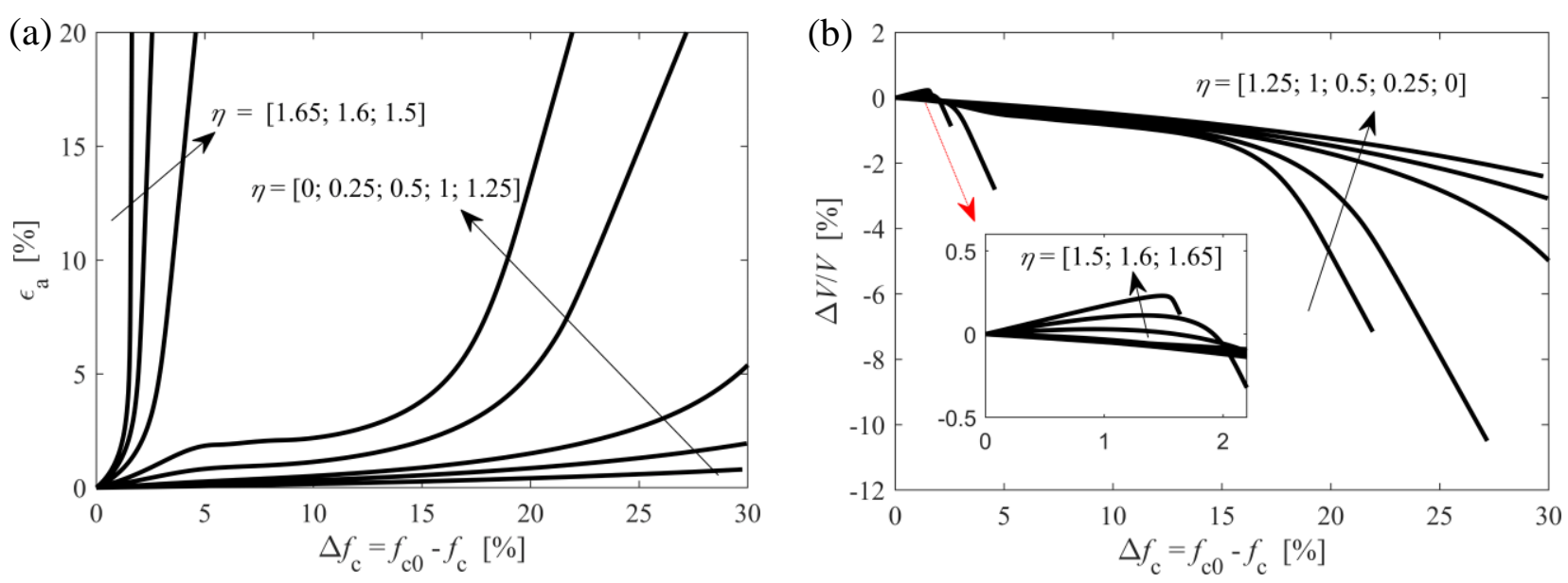

Figure 10. Specimen deformations as a function of the eroded fraction of fine particles in the simulations of erosion for different stress ratios : (a) axial strains; (b) volumetric strains 


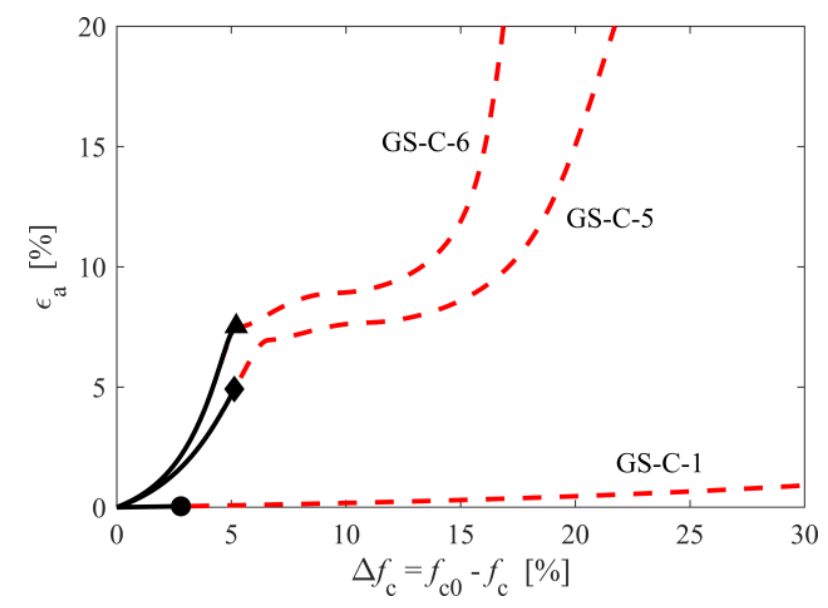

Figure 11. Simulated results of the calibrated erosion tests with continuing fines loss 

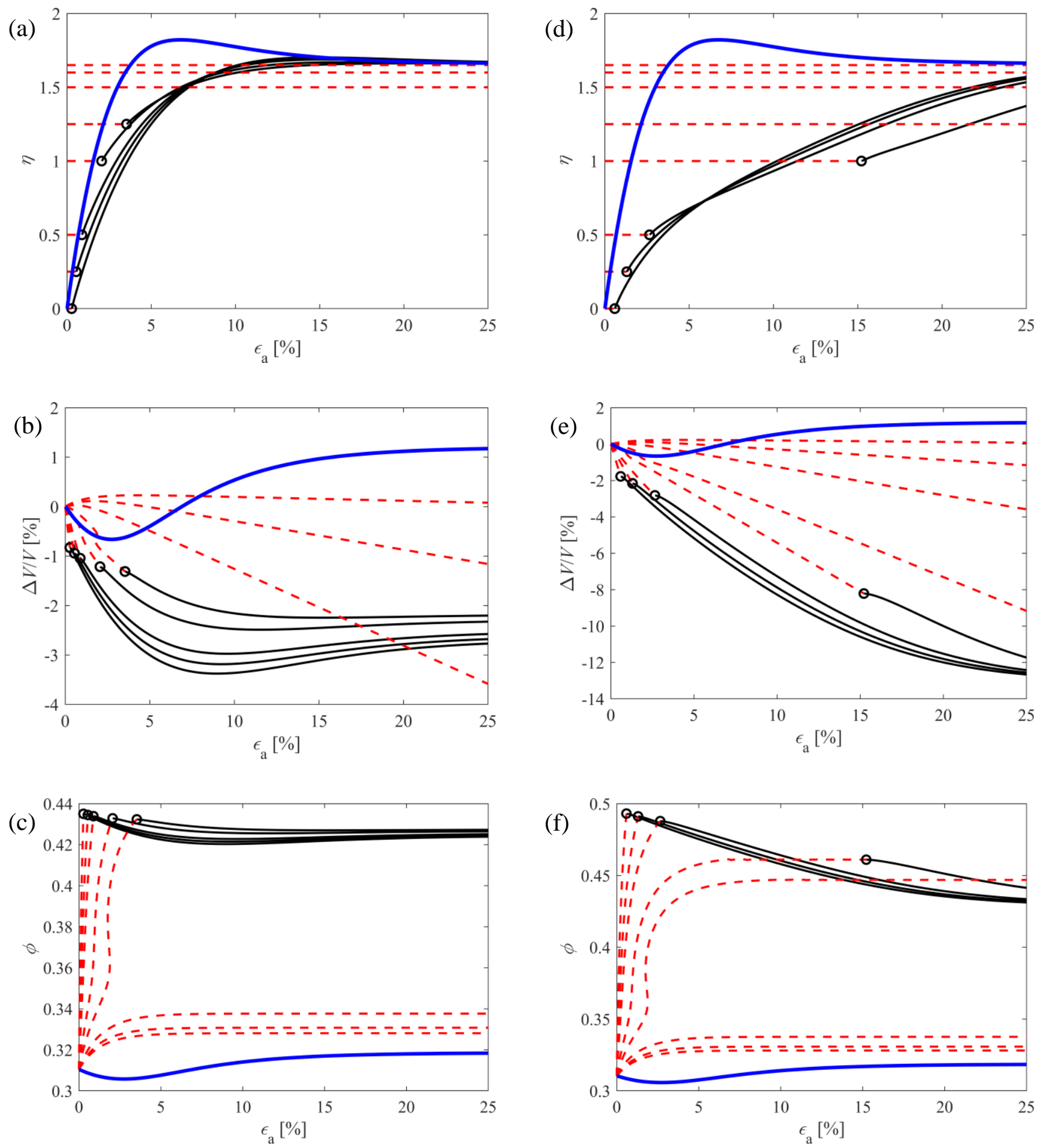

Figure 12. Simulations of erosion for different stress ratio and the following triaxial compression which stabilized at for (a - c), and for (d - f), respectively: the thick blue

lines indicate the triaxial compression of the initial specimen, the dashed thin lines indicate the erosion process, the solid lines indicate the following triaxial compression of the eroded samples 

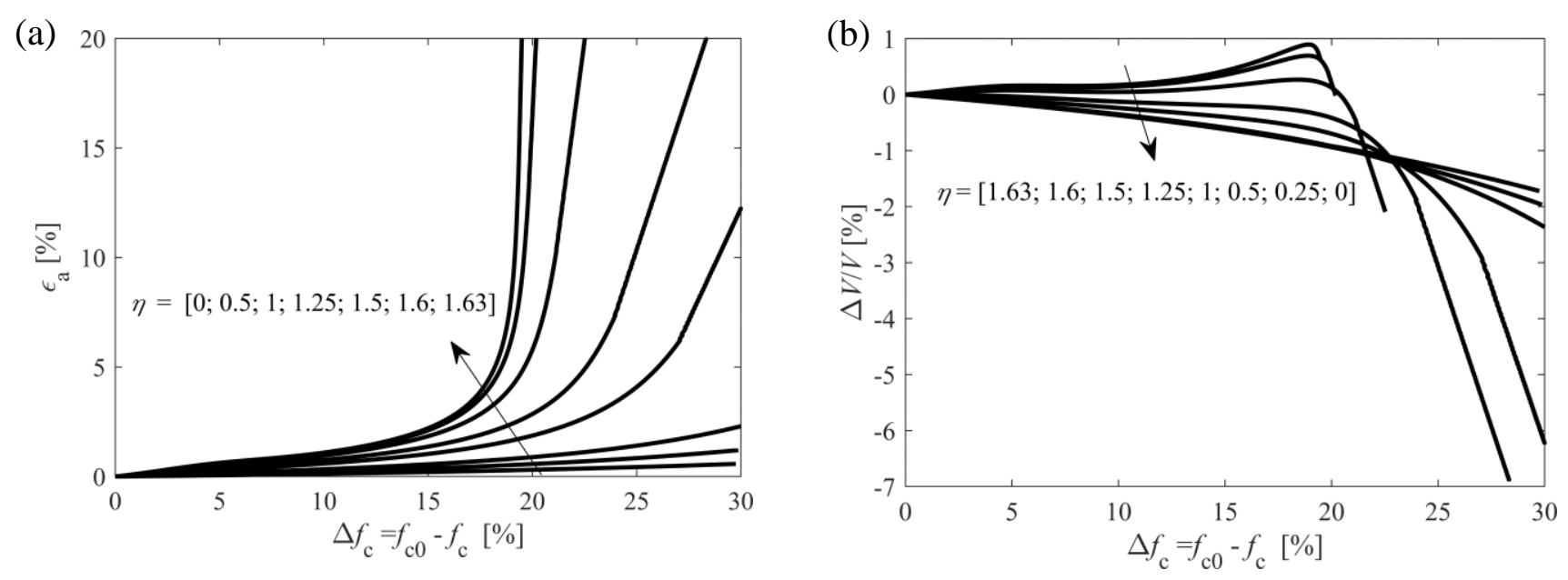

Figure 13. Specimen deformations in the simulations of erosion for different stress ratio on dense HK-CDG mixture with : (a) axial strains and (b) volumetric strains as a function of eroded fraction of fine particles. 
(a)
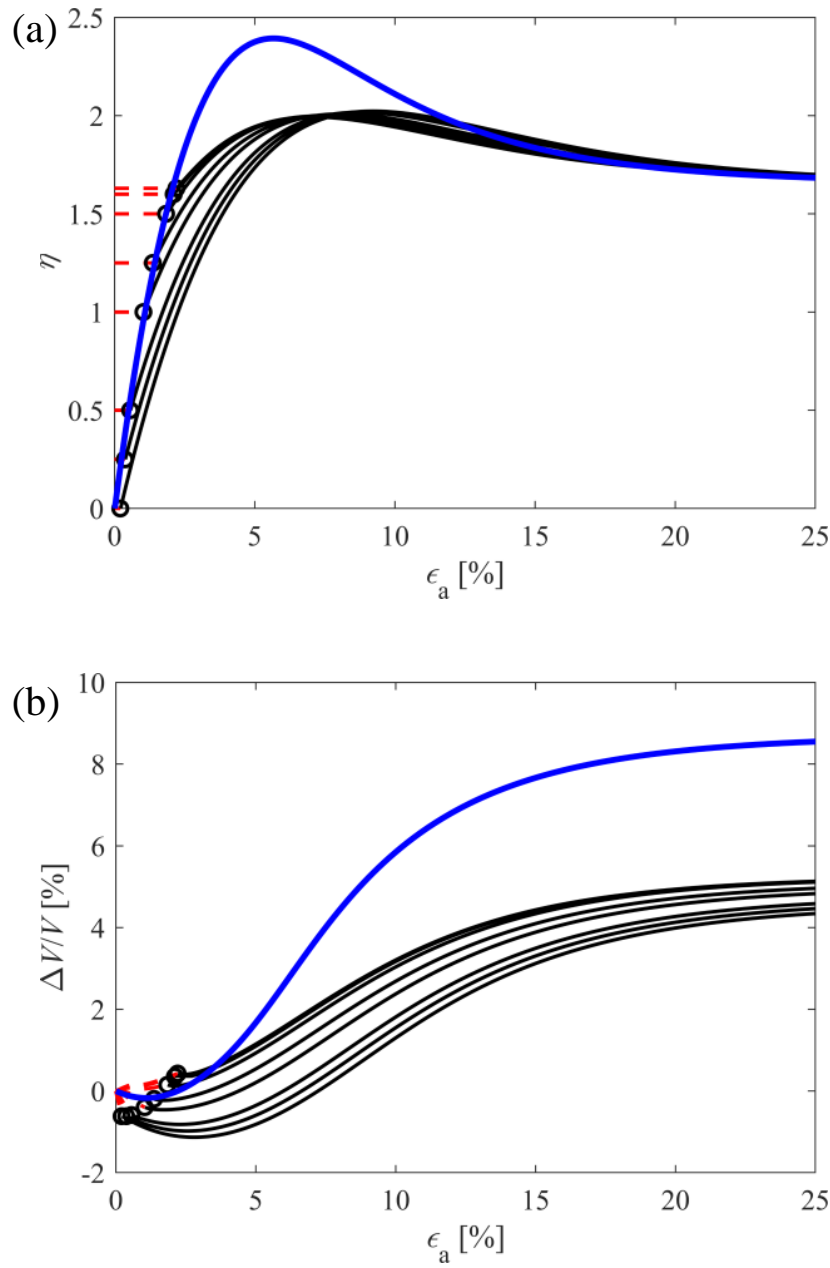

(c)

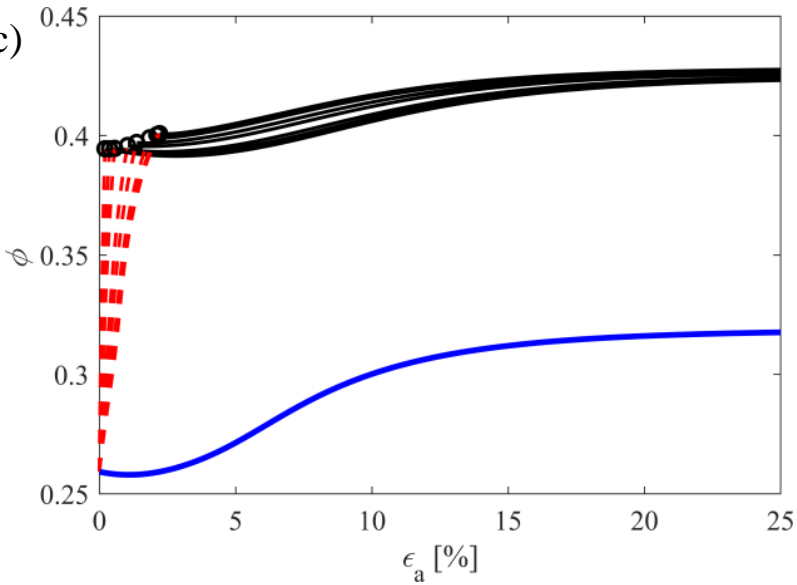

(d)
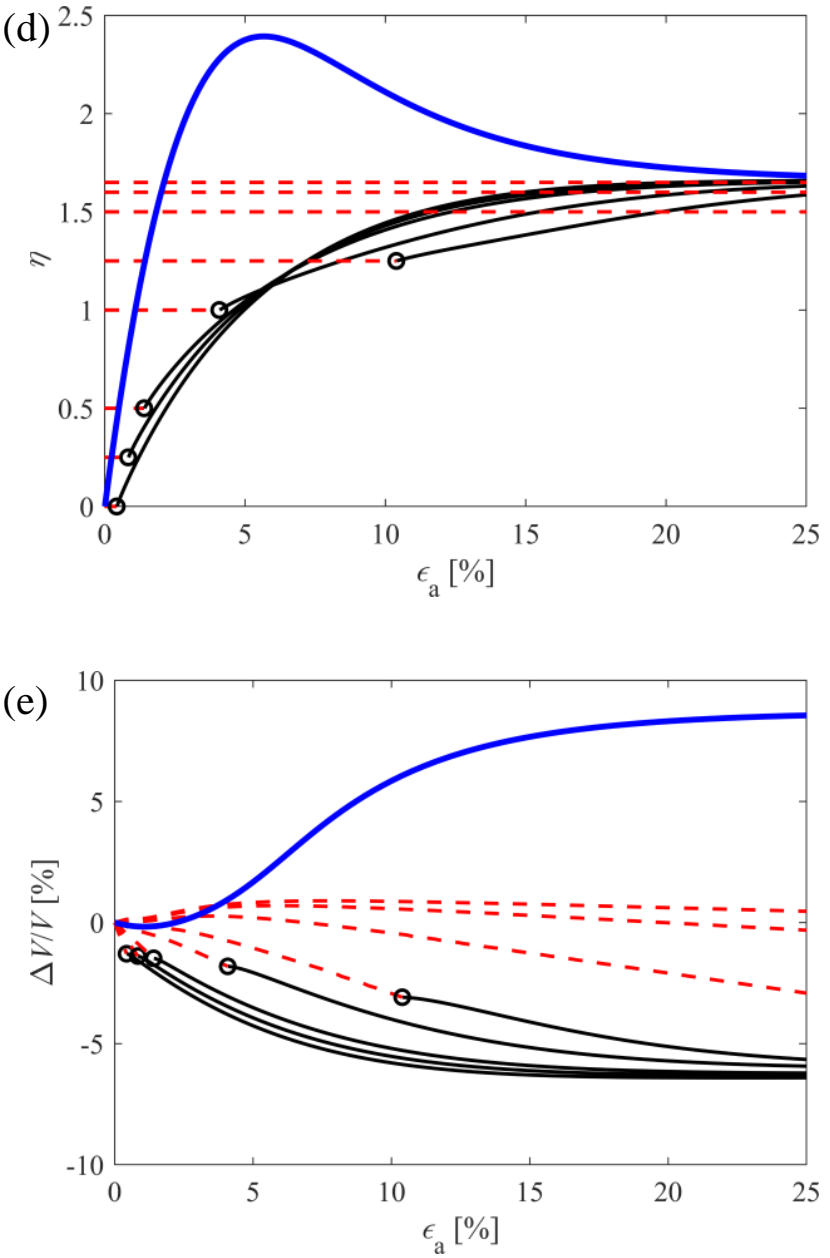

(f)

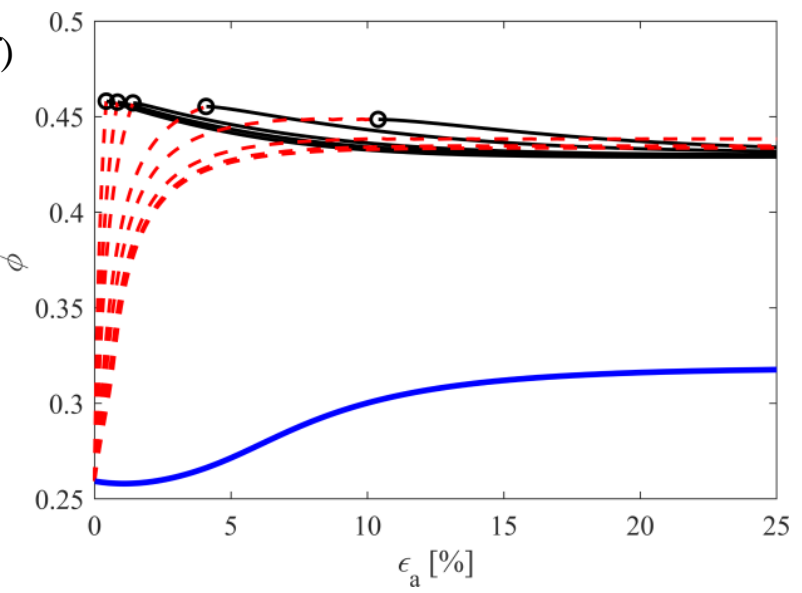

Figure 14. Simulations of erosion on initially dense HK-CDG mixture with for different stress ratio and the following triaxial compression which stabilized at for (a-c), and for (d-f) respectively: thick blue lines indicate the triaxial compression of the initial specimen, dashed thin lines indicate the erosion process, solid lines indicate the triaxial compression of the eroded samples 

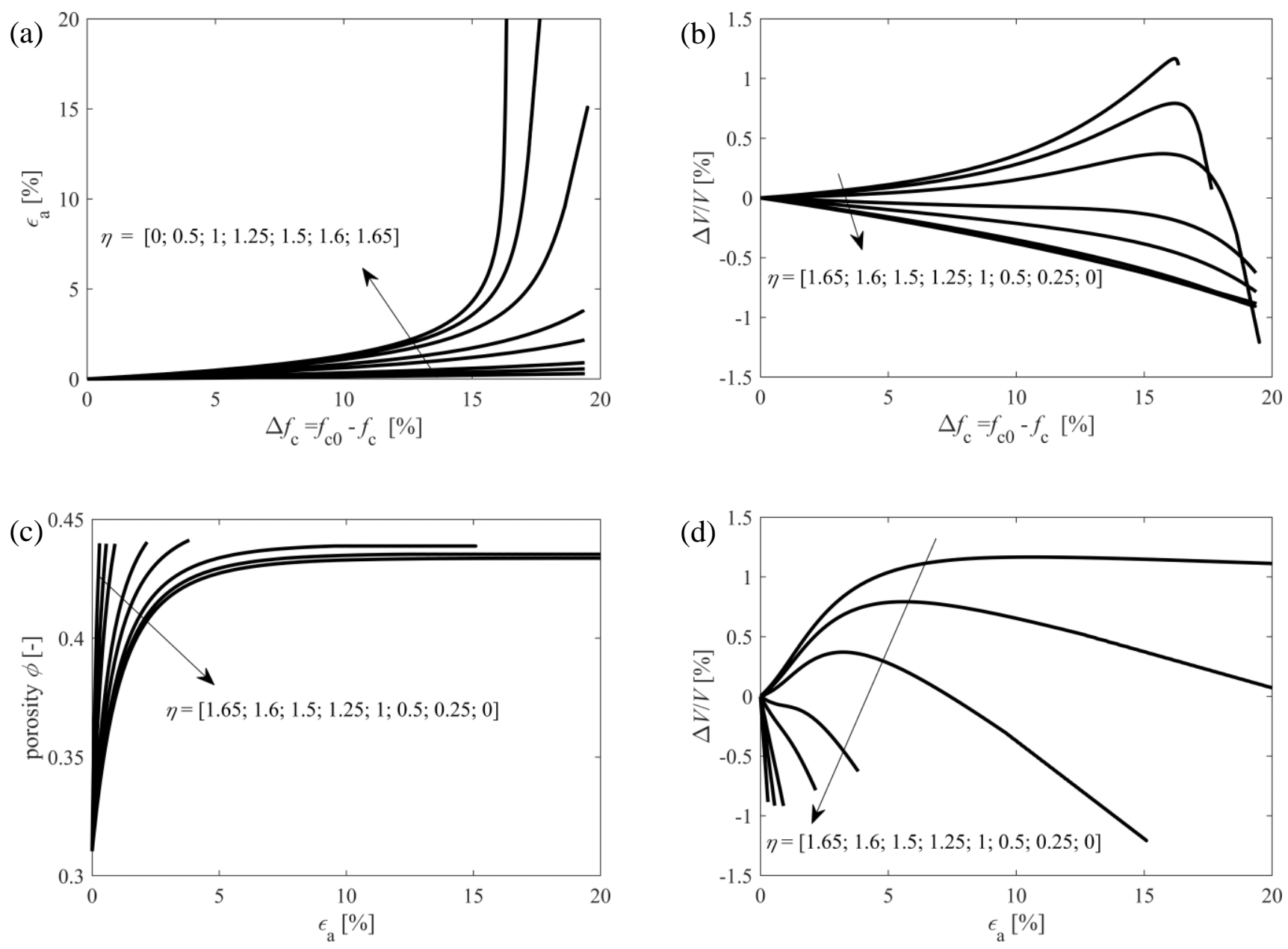

Figure 15. Specimen deformations in the simulations of erosion for different stress ratios on sand mixture with : $(a, b)$ axial and volumetric strains as a function of the eroded fraction of fine particles; $(\mathrm{c}, \mathrm{d})$ porosity and volumetric strain as a function of axial strain. 